\title{
Copying strategies of late Middle English scribes: Hand(s) and language(s) of two $15^{\text {th }}$-century manuscripts
}

\author{
María José Carrillo-Linares \\ University of Huelva
}

\begin{abstract}
The purpose of this paper is to compare two $15^{\text {th }}$-century manuscripts, Cambridge, University Library Kk.1.3 and Oxford, Bodleian Library Hatton 50, focusing on both paleographical and linguistic aspects. Samples from different sections of both manuscripts have been transcribed from either the original manuscripts or digital photographic reproductions. Each word and morpheme have been lexico-grammatically tagged to evaluate the scribe's linguistic behaviour with respect to spelling, phonology, and morphology. Paleographical and linguistic data to support the two main conclusions of the study are offered. With this analysis, I conclude that both manuscripts are, almost certainly, copied by the same person. Comparison of the different copying strategies generated by this single scribe allows us to achieve a better understanding of the written material in which Middle English has been preserved.
\end{abstract}

Keywords: linguistic variation; Middle English; paleography; scribes

\section{Introduction}

Oxford, Bodleian Library, Hatton 50 (henceforth Hatt50) contains a copy of the prose Brut Chronicle. The whole manuscript is written on parchment with a total number of 131 folios and paginated in modern pencil. The marginal headings are in red and there are catchwords at the end and beginning of each quire. Folio 1 has an illuminated initial ' $\mathrm{T}$ ' and is decorated with a border in the left, top, and bottom margins. In the running text there are two-line initials in red ink. A rubricated explicit on $\mathrm{f}$. 130v reads: "Here endith a book callyd Brute of the Croniculis of Englonde made \& compilid by notabill clerkis of all the

AUTHOR, Selim25 (2020): 121-172.

ISSN 1132-631X / DOI: https://doi.org/10.17811/selim.25.2020.121-172 
actis \& dedis of kyngis pat evir were in this londe to take exsaumpill what fil to fore our dayes".

According to Mooney \& Matheson (2003: 364-368), this manuscript is the product of three different scribes. ${ }^{1}$ The first one is the so-called Beryn Scribe, ${ }^{2}$ who copied folios $2 \mathrm{r}-17 \mathrm{v}$ (quires 1 and 2), $84 \mathrm{v}-107 \mathrm{r}$ (second half of quire 10 and quires 11,12 , and 13), and $119 \mathrm{r}-130 \mathrm{v}$ (second half of quire 15 and quire 16). Two other scribes supplied the rest of the text: Hand B copied folios 18r$25 \mathrm{v}$ (quire 3 ) and $80 \mathrm{r}-84 \mathrm{v}$ (half of quire 10). Hand $\mathrm{C}$ was responsible for folios $26 \mathrm{r}-79 \mathrm{v}$ (quires 4-9) and 108r-119r (quire 14 and half of quire 15). The Beryn Scribe took over from each of the other two scribes in the middle of a page (f. $84 v$ ) or in the middle of a quire (f. 119r).

As it stands today, Cambridge, University Library, Kk.1.3 (henceforth CULKk.1.3) is a volume rebound in 1976. Part 2 of one original volume was broken into four parts. At present, parts 10, 11, and 12 are bound together. Part 10 includes a copy of John Lydgate's Life of Our Lady, and it is believed to have been copied by the Beryn Scribe (Mooney \& Matheson 2003: 347-348). Part 11 is a copy of Thomas Hoccleve's Regiment of Princes and occupies seventy-nine folios. Modern pencil foliation has been added in upper outer corners on every recto. In both part 10 and 11 the layout of the text is similar, and the intended two-line word initials are left unfinished. In part 11 some of these initials have been added in black ink but most of them have not. Part 10 contains thirty to thirty-four lines to a page, while part 11 pages have thirty-four or thirty-five lines to a page. The watermarks ${ }^{3}$ in part 10 are a dragon (pp. 59, 60, 63, 93) and a bull's head (p. 3). In part 11 the watermark is a bull, but different from that found in part 10, p. 3. Part 12 contains two items: (i) 'vita trium regium colonie' in a small $15^{\text {th }}$-century hand, and (ii) 'Versus Barnardi'. This part has different watermarks and layout of the text.

Mosser \& Mooney (2014: 72-73) suggest that the hand of the Regiment of Princes in CULKk.1.3 (part 11) is Hand B of the Hatt50 copy of the Brut Chronicle. They make this claim on paleographical grounds and they state that the spelling evidence is inconclusive. Accepting that in both Hatt50 and CULKk.1.3 the same two scribes (the Beryn Scribe and Hand B) were copying

\footnotetext{
${ }^{1}$ See also Summary Catalogue, Vol. 2, Part II, p. 845.

${ }^{2}$ Mooney \& Matheson (2003) characterised this scribe as such because he copied the only extant copy of the Tale of Beryn in Northumberland, Alnwick Castle 455.

${ }^{3}$ Mosser (2010) describes watermarks in the paper stock used by the Beryn Scribe, who copied part 10 in this manuscript.
} 
different sections of the same manuscript production, they use this fact as part of their evidence to claim that the Beryn Scribe worked in recurrent collaboration with other scribes in a commercial centre in London to produce multiple copies of the same work. They also conclude that Hand B "is easily influenced by forms in his exemplars, and that the occasional resort to spellings associated with the repertoire of the Beryn Scribe suggests that some of these exemplars were prepared by him" (2014: 74). These authors offer no evidence for this claim.

The aim of this paper is not to reach any conclusions about when, where, or under what circumstances $15^{\text {th }}$-century scribes undertook their tasks, but to analyse these two particular manuscripts, focusing both on paleographical issues and on the linguistic features of Hand B of Hatt50 and of the hand of CULKk.1.3 (part 11). By first examining the paleographical details, we can investigate the claim of a common scribe for both texts. In the event that we are indeed dealing with the same hand, we may compare the scribe's copying strategies when working with two works written in different styles, with different origins, and different language features. Such studies will allow us to achieve a better understanding of the written material in which Middle English has been preserved. The actual and final result of the copying process, that is, the text as we have found it, with a particular layout, writing conventions, or language features is the product of the interaction of its copyist with the material portrayed in his source text or 'exemplar'. A medieval scribe had to decide how much of his exemplar he wanted to preserve in the same shape: whether he wanted to use the same calligraphic style, formatting and layout, or language of his original copy, or, on the contrary, alter some or all of these aspects.

As for the linguistic aspects, McIntosh (1974: 61 [1989: 92]) proposed the three strategies that a scribe might adopt: (1) copy literatim; (2) 'translate' the dialect of the exemplar into the copyist's own dialect; (3) partly copy, partly 'translate'. The distance between the original copy of any work and the actual one that has come to us is determined by the number of intermediate copies between them, and the time elapsed between the original and the extant copy. When production increased considerably during the $14^{\text {th }}$ and $15^{\text {th }}$ centuries, successive copying might result in texts with multiple language layers. The consistency in language features depends entirely on the scribe's abilities to 'translate' into his more spontaneous linguistic usage. However, in many cases the scribes were familiar with multiple forms which they might have adopted into their active linguistic repertoire as a consequence of making several copies 
of the same work, ${ }^{4}$ generating thus diverse texts with apparent inconsistent language. If the texts were in verse form, the copyist had other textual constraints since, additionally, he had to deal with rhyme, metre, or alliteration. Translating then became more problematic since alterations could produce disruption to the metrical scheme. In any case, as Benskin \& Laing (1981: 56) pointed out, "a copyist may shift from one type of treatment to another, and a transitional drift from type C to type B is in fact very common".

The copying environment in the early $15^{\text {th }}$ century has been a topic of debate. Doyle \& Parkes (1978: 170-174) found no evidence to indicate that most copies produced in the early $15^{\text {th }}$ century were the work of a scriptorium. Instead, independent craftsmen were hired when required, and some of these scribes might have worked outside the trade. Christianson (1989: 96) argues that "instead of labouring in large work spaces, many artisans may have worked independently in small quarters, not in concert in a single shop, and a book was therefore created on many different sites". Taylor (2003: 2) even suggests that "if a scribe wanted to produce a large book in a hurry, he could farm out sections to his neighbours, or call on one of them to complete the rubrication or decoration".

The scribes copying in the $15^{\text {th }}$ century undertook different tasks during their career. Some of them can be identified while many others remain anonymous. Mooney, Horobin \& Stubbs' Late Medieval English Scribes website stores data with the aim of identifying scribes who copied major literary works. In their website, they set "an image of each scribal hand in each medieval or early modern manuscript of the English writings of five principal authors of the late fourteenth and early fifteenth centuries: William Langland, Geoffrey Chaucer, John Gower, John Trevisa and Thomas Hoccleve." Some of these hands seem to have been responsible for the copying of other works outside this canon. However, the evidence in the database suggests that some of the scribes specialised in some particular authors' works. It also implies collaborative work among the scribes.

Horobin (2009: 193) states that the so-called Edmund-Fremund Scribe specialised in the works of Lydgate and was based in a commercial workshop at the Abbey of Bury St Edmund, although this same scribe was also responsible for a copy of Chaucer's Canterbury Tales. Some other scribes were very prolific, and although there are several extant manuscripts of their production, a fact

\footnotetext{
${ }^{4}$ For a study of this circumstance in the writings of the Beryn Scribe, see CarrilloLinares \& Williamson (2019) and Carrillo-Linares \& Williamson (2020).
} 
which points towards this specialisation, they also copied other popular works. ${ }^{5}$ Horobin \& Mooney (2004) argue that the scribe of two major manuscripts of the Canterbury Tales ${ }^{6}$ is also responsible for the copying of one of the manuscripts of Piers Plowman B text. ${ }^{7}$ Mooney (2006: 98-99) claims that one Adam Pinkhurst was 'Chaucer's Scribe' and that he was responsible for the copying of the Ellesmere and Hengwrt manuscripts of the Canterbury Tales, one manuscript Gower's Confessio Amantis, ${ }^{8}$ a fragment of a single leaf of Chaucer's Troilus and Criseyde, ${ }^{9}$ another single leaf of the Canterbury Tales in CULKk.1.3 (part 20), an acephalous copy of Chaucer's Boece, ${ }^{10}$ a copy of Langland's Piers Plowman B text, ${ }^{11}$ some prose tracts, including Wycliffite, ${ }^{12}$ and several other documents. $^{13}$

On other occasions, groups of scribes sharing some paleographical features are said to have worked together, such as is evidenced by the group of manuscripts attributed to the so-called 'hooked- $g$ scribes', who are believed to have undertaken three copies of Chaucer's Canterbury Tales, ${ }^{14}$ four of Gower's

\footnotetext{
${ }^{5}$ Scribe D in Cambridge, Trinity College R.3.2 (a copy of Gower's Confessio Amantis) was identified by Doyle \& Parkes (1978). He seems to be also responsible for the copies of this work found in: Oxford, Corpus Christi College 67; Oxford, Bodleian Library, Bodley 902; Oxford, Christ Church, 148; New York, Columbia University Library, Plimpton 265; London, British Library, Egerton 1991; Oxford, Bodleian Library, Bodley 294; Cambridge, Trinity College R.3.2; Princeton University Library, Taylor 5. Besides, he also copied two manuscripts of the Canterbury Tales: London, British Library, Harley 7334, and Oxford, Corpus Christi College 198; one manuscript of Piers Plowman: London, University Library, V.88; and one of Trevisa's De Proprietatibus rerum: London, British Library, Additional 27944.

${ }^{6}$ San Marino, Huntington Library MS EL 26 C.9 (Ellesmere); Aberystwyth, National Library of Wales MS Peniarth 392D (Hengwrt).

${ }^{7}$ Cambridge, Trinity College B.15.17.

${ }^{8}$ Cambridge, Trinity College R.3.2 (581), fols. 9r-32v.

${ }^{9}$ Hatfield House, Herts., Cecil Papers, Box S/1.

${ }^{10}$ Aberystwyth, National Library of Wales MS Peniarth 393D.

${ }^{11}$ See note 7 above.

${ }^{12}$ Dublin, Trinity College 244.

13 See Warner (2018: 32) for a detailed and comprehensive description of these manuscripts.

${ }^{14}$ New Haven, Yale University Beinecke Library Takamiya 24; Cambridge, Trinity College R.3.3; Oxford, Bodleian Rawlinson poet. 223.
} 
Confessio Amantis, ${ }^{15}$ four of Lydgate's Fall of Princes, ${ }^{16}$ two of Lydgate's Troy Book, ${ }^{17}$ one of Trevisa's Polychronicon, ${ }^{18}$ one of Chaucer's Troilus and Criseyde,${ }^{19}$ as well as three separated fragments of a single manuscript of the Fall of Princes ${ }^{20}$ (Mosser \& Mooney 2016). Warner (2018) challenges some of the attributions made by Mooney and her collaborators of London literary scribes, providing a sharp critique of the methodology they have employed to come to their conclusions.

Other scribes copied multiple works from different origins and sources, different types of language employing a number of different dialectal types in a single manuscript. An example of this is the scribe of Oxford, Bodleian Library, Digby 84 , who produced, as a whole, a text with a language with multiple layers (Laing 2000). The Beryn Scribe was responsible for copying a number of popular contemporary works. These include several manuscripts of the prose Brut Cbronicle, ${ }^{21}$ some of the stories of the Canterbury Tales ${ }^{22}$ and the unique Tale of Beryn, ${ }^{23}$ the Oxford fragments of Canterbury Tales, ${ }^{24}$ one text of the Main Version of the Prick of Conscience, a version of the Chronicle of London, a copy of Chaucer's Parlement of Foules, Statues and Ordinances for the Army by Henry

\footnotetext{
${ }^{15}$ Oxford, Bodleian Library, Lyell 31; London, British Library, Harley 7184; Oxford, Magdalen College, Lat. 213; Washington, Folger Library V. b. 29.

${ }^{16}$ London, British Library, Additional 21410; London, Lambeth Palace 256; Oxford, Bodleian Library Hatton 2; New Haven, Yale University Beinecke Library, Takamiya 30.

${ }^{17}$ London, British Library, Royal 18 D. vi; Oxford, Exeter College 129.

${ }^{18}$ Princeton, University Library, Taylor 6. (1).

${ }^{19}$ London, British Library, Harley 3943.

${ }^{20}$ New York, Columbia University Library, Plimpton 255; Philadelphia, Free Library, Lewis T.15/487; New Haven, Yale University Beinecke Library, Takamiya 79.

${ }^{21} \mathrm{He}$ is responsible for two manuscripts containing complete copies of the prose Brut Chronicle: London, British Library Harley 1337; London, British Library Harley 6251; and Oxford, Bodleian Library Rawlinson C. 901. He also wrote lengthy portions of the Brut Chronicle in three other manuscripts: Ann Arbor, University of Michigan, Hatcher Library, 225; Oxford, Bodleian Library, Hatton 50; and Oxford, Bodleian Library, Tanner 11.

${ }^{22}$ Alnwick Castle, Duke of Northumberland, 455; Princeton Firestone Library, 100.

${ }^{23}$ Alnwick Castle, Duke of Northumberland, 455.

${ }^{24}$ Rosenbach 1084/2 and Manchester, John Rylands Library English 63.
} 
$V^{25}$ and a version of John Lydgate's Life of Our Lady ${ }^{26}$ Carrillo-Linares \& Williamson (2020) consider that "having different models for each of his productions, he [the Beryn Scribe] was led in each of them to produce a language with different layers of different depths", even if there are certain idiosyncratic features which are consistent across his productions.

It is my understanding that this same principle could be applied to many other $15^{\text {th }}$-century scribes who made multiple copies of diverse works. To determine how typical these copying practices were among professional copyists requires investigation of other cases of manuscripts in the same hand and comparison of their language. The evidence collected by Mooney, Horobin \& Stubbs, and gathered in the Late Medieval English Scribes website, points to the fact that, although some scribes have been ascribed only works of the same kind or by the same author, there are many others who seem to have copied pieces with less in common. The linguistic analysis of texts which are the result of multiple layers of copying is, at the very least, daring, when it comes to reach general conclusions about the state of the language in the Middle English period. This is essentially so because of the process of transmission and the nature of the resulting output. It is essential to understand the underlying facts and issues to be able to interpret the data accurately. It is not always possible to figure out how much of a text has been inherited from an exemplar and how much is the reflection of the scribe's language. Minority forms in a text can be interpreted in various ways, since they can be seen as relics carried over from the exemplar, or, on the contrary, as the spontaneous usage of the scribe. This paper, along with my previous work on the topic, aims to contributing some pieces to fill some of the gaps in the massive jigsaw puzzle that is the history of English.

\section{Data and methodology}

The sources of the data for this paper are mainly the manuscripts Hatt50 and CULKk.1.3, complemented with data from other manuscripts whose copying has been attributed to the Beryn Scribe, as he participates in the copying of Hatt50 and CULKk.1.3. For Hatt50, samples from all portions copied by the three different scribes have been transcribed to disk. Transcription was made

\footnotetext{
${ }^{25}$ All these are found in a single volume in Oxford, St John's College 57.

${ }^{26}$ Cambridge, University Library, Kk.1.3 (part 10).
} 
from either the original manuscripts or digital photographic reproductions. ${ }^{27}$ From the transcribed texts I tagged each word and morpheme lexicogrammatically in order to be able to evaluate the scribe's linguistic behaviour with respect to spelling, phonology, and morphology. Lexico-grammatical tagging involves adding a label comprising a lexical element and/or a grammatical element to the words found in the manuscript text. All the features recorded were examined and assessed comparing occurrences in all the samples. I created Linguistic Profiles (henceforth LPs) using an extended version of the Questionnaire in the electronic version of $A$ Linguistic Atlas of Late Medieval English (henceforth e-LALME) to include some further items that seemed relevant for the copying practice of the scribe. The forms and features displayed in the LPs have been compared, and for the present paper a smaller selection of items for the analysis is presented. ${ }^{28}$ As a point of reference for occurrence of

${ }^{27}$ I am grateful to the staff in the Manuscripts Reading Room at Cambridge University Library for their help during my visits to the library (31 October to 5 November 2017 and 21 October to 14 November 2019) and for allowing me to transcribe from manuscript Kk.1.3 and to take images from it; likewise, to the staff in Oxford, Bodleian Weston Library for letting me take photos from their manuscripts (6-10 August 2018) and providing me with digital copies. Reproduction of images from Ms Hatton 50, ff. $18 \mathrm{r}-25 \mathrm{v}$ have been kindly granted by The Bodleian Libraries, The University of Oxford. Images from Cambridge University Library Kk.1.3 are reproduced by kind permission of the Syndics of Cambridge University Library.

${ }^{28}$ Tables including eighty-two items and features have been produced form the LPs for the analysis presented here. These items are organised in various categories: (1) Common words including the items AGAIN, AGAINST, ANY, ARE, BEFORE, BOTH, BROTHER, CHURCH, DAUGHTER, DEATH, DOES, EACH, EITHER, FELL, FIRE, GAVE, GOES, HAVE, IF, IT, HIS, LAND, MANY, MOTHER, MUCH, NEITHER...NOR, NOT, ONE, PEOPLE, SAW, SHALL, SHOULD, STRENGTH, SUCH, THAN, THEE, THE-ONE, THE-OTHER, THEIR, THEM, THEN, THESE, THEY, THOU, THROUGH, THY, TWO, UPON, WAS, WERE, WHEN, WHERE, WHICH, WHILE, WIGHT, WILL, WITEN, WORLD, YE, YEAR, YOU, YOUR. (2) Grammatical features, including 'Substantive Plural', '3rd Person Singular Present Indicative', 'Plural Present Indicative', 'Weak Past', 'Weak Past Participle', 'Present Participle', 'Past Participle Prefix', 'Infinitive Ending', 'Negation with NE'. (3) Items related to spelling or phonology, including prefixes -ABLE, -LY, and -ASE (for -ACE), combination of syllables as <atte $>$ (for AT THE), spelling of $<\mathrm{v}\rangle$ for etymological $/ \mathrm{w} /$, use of $\langle\mathrm{v}>$ or $<\mathrm{u}>$ for non-initial $/ \mathrm{v} /$, preference for $\langle\mathrm{sh}>$ or $<\mathrm{sch}>$ for sound / $\int /$, 'h' dropping, non-etymological ' $h$ ' insertion, spelling reflexes for $\mathrm{OE} / \mathrm{x} /$, the distribution of ' $w$ ', the sequence 'wh'. 
some of the forms in the resulting LPs, this study draws on those originally collected for LALME. These can be accessed on-line through the 'electronic version'. In discussions of the dialectal character of certain items, I refer to the e-LALME 'Dot Maps' which show the geographical distribution of forms collected in the LPs. To supplement the Dot Maps (henceforth DM) and access more diatopic detail, I have also used the 'User-defined Map' function available in e-LALME.

This paper has two main sections. (1) The first one is essentially descriptive and devoted to paleographical details, and its aim is to compare the scripts in both manuscripts to attest the scribal identity of both copies. For this section, data for various letter formations have been collected. These figurae for letters are considered in isolation as well as in context, but in the examples provided in each case the whole word in which a letter occurs is shown. A parallel selection from both texts showing the formation of the letters where they occur in equivalent contexts, i.e. in the same sequence of letters (same word) is given in the appendices. (2) The second section provides details and interpretation of the selected linguistic forms and features.

\section{Paleographical details}

According to Mooser \& Mooney (2014: 72-73), "[t] he hand of the Regiment [in CULKk.1.3 (part 11)] appears, on paleographical grounds, to be that of Hand B in the Hatton 50 copy of the Brut." These authors only point out the similarities of "aspects and of formation of the letters $w$, secretary $g, d$ with looped ascender, $y$ which is frequently dotted and has a sharp turning to the right at base of the descender, and upper case $B$." Since these features are far too few and general and shared by many scribes in the $15^{\text {th }}$ century, a closer and more detailed look at the general aspect, duct, and letter formation exhibited in both texts is required to draw more accurate conclusions about the scribe/s of both pieces. At first sight, there are certainly many similarities between both hands, although, as Mosser \& Mooney (2014: 73-74) also state, "[i]n writing the prose Brut, this scribe uses a looser, less formal hand than when writing verse in Hoccleve's Regiment." A description of some of the isolated letters in both manuscripts will be carried out first. ${ }^{29}$

\footnotetext{
${ }^{29}$ Images corresponding to the descriptions of the letters are included in Appendices 1 and 2 for CULKk.1.3 (part 11) and Hatt50 respectively.
} 
3.1. Description of the figurae in Cambridge University Library Kk.1.3 (part 11) and Oxford, Bodleian Library Hatton 50

\section{Cambridge University Library Oxford, Bodleian Library Kk.1.3 (part 11) Hatton 50}

<a> Two-compartment 'a' is used Two-compartment 'a' is used throughout. The shape varies throughout. The shape varies slightly but is consistent. The somewhat within the limits of same shape occurs both in initial consistency, e.g. <aftir $>$ f. $18 \mathrm{v}$, position, e.g. <atte $>$ f. 9 v, <agoo $><$ agayne $>$ f. 23 r, <as $>$ f. $19 \mathrm{r}$ in f. $5 \mathrm{r},<$ as $>$ f. $5 \mathrm{v}$; and in medial initial position; and $<$ have $>\mathrm{f}$. position, e.g. <grave> f. $5 \mathrm{r}, 24 \mathrm{v}$, <schall> f. $19 \mathrm{r},<$ make $>\mathrm{f}$. $<$ shall $>$ f. 5 v, $<$ make $>$ f. $1 \mathrm{r}$. $\quad 22 \mathrm{r}$ in medial position. 


\begin{tabular}{l} 
Cambridge University Library $\begin{array}{l}\text { Oxford, Bodleian Library } \\
\text { Katton } 50\end{array}$ \\
\hline$<d>\quad$ There are three formations for $\quad$ It is looped and the lower lobe is \\
this letter:
\end{tabular}




\begin{tabular}{|c|c|c|}
\hline & $\begin{array}{l}\text { Cambridge University Library } \\
\text { Kk.1.3 (part 11) }\end{array}$ & $\begin{array}{ll}\text { Oxford, Bodleian } & \text { Library } \\
\text { Hatton } 50 & \end{array}$ \\
\hline$\langle g\rangle$ & $\begin{array}{l}\text { There are two types: } \\
\text { (1) A two-compartment 'g', e.g. } \\
\text { <grave> f. 5r (initial position), } \\
\text { <pought> f. } 2 \text { r (medial position). } \\
\text { (2) A kind of secretary 'g' with a } \\
\text { horizontal cross-bar, e.g. <agoo> } \\
\text { f. 5r (initial position), } \\
\text { <almyghty> f. 11v, (medial } \\
\text { position), <being> f. 13r (final } \\
\text { position). }\end{array}$ & $\begin{array}{l}\text { Secretary type with a horizontal } \\
\text { cross-bar, e.g. <grete> f. } 18 \mathrm{r} \\
\text { (initial position), <agayne>f. } 23 \mathrm{r} \text {, } \\
\text { (medial position), <fizting }>\text { f. } 23 \mathrm{r} \\
\text { (final position). } \\
\text { It seems to be a rapidly-made } \\
\text { form with the left arm curving to } \\
\text { the left and the cross-bar joining } \\
\text { both arms. Occasionally, a tail } \\
\text { stroke of the left hand joins both } \\
\text { stokes as well, e.g. <gouernyd }>\mathrm{f} \text {. } \\
\text { 18r. }\end{array}$ \\
\hline
\end{tabular}
$<b>\quad$ Has an arch head stroke which Has an arch head stroke which can be: can be:
(1) Completely close joining up with the tail stroke, e.g. <wiche> f. $5 \mathrm{v}$.
(1) Completely close, joining up with the tail stroke, e.g. <othir> f. 18 r.
(2) Open and neatly executed, e.g. <with> f. 2v. The tail stroke usually flicks to the left beneath the body of the graph, e.g. $<$ with $>$ f. 2 v, <hyt $>$ f. $3 r$, <his $>$ f. $1 \mathrm{r}$; and, occasionally, it is just a neat vertical stroke, e.g. <schall> f. $3 r,<$ wiche $>$ f. $5 \mathrm{v}$.
(2) It can be open, e.g. <have> f. 21r. The tail stroke usually flicks to the left beneath the body of the graph, e.g. <have> f. 21r, <might> f. 18r, <hem> f. 19r; or it is just a neat vertical stroke, e.g. <othir> f. 18r, <hem> f. 19v.




\begin{tabular}{|c|c|}
\hline & $\begin{array}{l}\text { Cambridge University Library } \\
\text { Kk.1.3 (part 11) }\end{array}$ \\
\hline$<r\rangle$ & $\begin{array}{l}\text { The scribe uses two types of <r> } \\
\text { which are very similar: } \\
\text { (1) It resembles a modern <r> } \\
\text { made with two strokes: a ' } \mathrm{\text {' }} \\
\text { shaped one and a horizontal } \\
\text { short bar lined up with the upper } \\
\text { part of the ' } \mathrm{z} \text { ' stroke, e.g. <aftir> } \\
\text { f. } 2 \mathrm{v} \text { (final position), <gretter }>\text { f. } \\
5 \mathrm{r} \text { (medial position), <renegate> } \\
\text { f. } 5 \mathrm{r} \text { (initial position). } \\
\text { (2) ' } \mathrm{z} \text { ' shaped, sometimes with a } \\
\text { flicked serif, e.g. <aright }>\text { f. } 2 \mathrm{r} \text {, } \\
<\text { brente> f. } 5 \mathrm{r} \text { (medial position), } \\
<\text { gretter }>\text { f. } 5 \mathrm{r} \text { (final position), } \\
<\text { relievid }>\text { f. } 4 \mathrm{v} \text { (initial position). }\end{array}$ \\
\hline & $\begin{array}{l}\text { Additionally, in initial position } \\
\text { there is a third type: } \\
\text { (3) Capitalised ' } r \text { ' is often } \\
\text { produced, e.g. <Riche> f. } 4 \text { r, } \\
\text { < Remedy> f. 4v. }\end{array}$ \\
\hline
\end{tabular}

\section{Oxford, Bodleian Library Hatton 50}

The scribe uses three very similar types:

(1) It resembles a modern $<r>$ made with two strokes and sometimes with a flourish, e.g. $<$ brothir $>$ f. 23r. It occurs mainly in word-final position, although, at times, it is used in medial position, e.g. <were> f. $24 \mathrm{r}$, and only rarely in initial position, e.g. $<$ rydyn $>$ f. 24 r.

(2) ' $z$ ' shape, with a horizontal short bar lined up with the upper part of the ' $z$ ' stroke, e.g. <her> f. $23 \mathrm{r},<$ aftir> f. $18 \mathrm{v}$.

(3) ' $z$ ' shape without the bar, in medial position, e.g. <brothir> f. 23r, <gouernyd> f. 18r; and occasionally in initial position, e.g. <robbid > f. 20r.

Additionally, in initial position there is another type:

(4) Capitalised ' $r$ ' is used in places where modern convention would not use a capital letter, e.g. $<$ Reste> f. 22v, <Rede> f. 25r. 


\begin{tabular}{|c|c|c|}
\hline & $\begin{array}{l}\text { Cambridge University Library } \\
\text { Kk.1.3 (part 11) }\end{array}$ & $\begin{array}{l}\text { Oxford, Bodleian Library } \\
\text { Hatton } 50\end{array}$ \\
\hline$\langle s\rangle$ & $\begin{array}{l}\text { The scribe makes use of two } \\
\text { types: } \\
\text { (1) Kidney-shaped, which is the } \\
\text { only one used in final position, } \\
\text { e.g. <is> f. 2r. } \\
\text { (2) A long 's' used in medial } \\
\text { position, e.g. <also> f. 7v; } \\
\text { initially in a word the preferred } \\
\text { form is also a long 's'. } \\
\text { Additionally, in word initial } \\
\text { position: } \\
\text { (3) Capital 's' is used throughout } \\
\text { in places that are not } \\
\text { conventionally capitalised in } \\
\text { present-day usage, e. } \\
\text { <Skynner> f. } 7 \mathrm{v} \text {. The capital 's' } \\
\text { occurs also in word initial at the } \\
\text { beginning of a line, e.g. <Shal }>\text { f. } \\
\text { 5v. }\end{array}$ & $\begin{array}{l}\text { The scribe makes use of two } \\
\text { types: } \\
\text { (1) Kidney-shaped is used } \\
\text { consistently in final position, e.g. } \\
\text { <as f. 19r, and occasionally in } \\
\text { initial position, e.g. <sone> f. } \\
\text { 18r. } \\
\text { (2) A long 's' is always used in } \\
\text { medial position, e.g. <azenste> f. } \\
24 \mathrm{v} \text {, <resseyuyd }>\text { f. } 21 \mathrm{v} \text {. It is also } \\
\text { found in initial position, e.g. } \\
\text { <stronge> f. 18v, <schulde> f. } \\
22 \mathrm{r} \text {. } \\
\text { Additionally, in initial position: } \\
\text { (3) Capital 's' is used throughout } \\
\text { in places that are not } \\
\text { conventionally capitalised in } \\
\text { present-day usage, e.g. <Shal> f. } \\
\text { 19r. }\end{array}$ \\
\hline
\end{tabular}

$\langle w\rangle \quad$ Modern-like graph. The only Modern-like graph. The only variation found is in the length of variation found is in the length of the approach stroke when it occurs initially, which sometimes extends somewhat down, e.g. $<$ were $>$ f. 2 r; and in others it is almost inexistent, e.g. <was $>\mathrm{f}$. $5 \mathrm{v}$. In medial or final position it joins up with the previous letter, e.g. <power $>$ f. 5 r, <thow $>$ f. 3 r. the approach stroke when it occurs initially, which sometimes extends downwards, e.g. <were> f. 24r, <was> f. 18r, and in others it is almost inexistent, e.g. <was > f. 23r, <were > f. 23r, <worlde> f. 21r. The same applies for occurrences in medial or final position, e.g. <power> f. $18 \mathrm{r}$, $<$ thow f. $24 \mathrm{r}$. 


\begin{tabular}{lll}
\hline & $\begin{array}{l}\text { Cambridge University Library } \\
\text { Kk.1.3 (part 11) }\end{array}$ & $\begin{array}{l}\text { Oxford, Bodleian Library } \\
\text { Hatton 50 }\end{array}$ \\
\hline$<y>\quad \begin{array}{l}\text { Usually shaped with a vertical } \\
\text { stroke for the left arm of the }\end{array}$ & $\begin{array}{l}\text { Usually shaped with a vertical } \\
\text { stroke for the left arm of the }\end{array}$ \\
letter, and a curved limb for the & $\begin{array}{l}\text { letter, and a curved limb for the } \\
\text { right whose descender continues } \\
\text { right whose descender continues }\end{array}$ \\
as a tail. It is frequently dotted, as a tail. It is frequently dotted, \\
e.g. <any> f. 5v, but not always, e.g. <any> f. 19r, but not always, \\
e.g. <any> f. 2v. Its appearance is & e.g. <aryyd $\mathrm{f}$. 19v. It has a \\
the same in medial or final & similar look in medial or final \\
position, e.g. <almyghty> f. 11v, position. It does not occur in \\
<3yf> f. 6r. It does not occur in
\end{tabular}
initial position.
$<v>$ In initial position the approach stroke of ' $v$ ' is shaped with a small tag at the top of the left limb, e.g. <vnbuxum> f. 15r. This shape is also found in medial position: e.g. <have> f. 5r, <grave> f. 5 r.
In both initial and medial position there is another type which resembles the shape of the $<b>$ the scribe uses, although it is less common. The left limb is at times slightly more oblique than that of the $\langle$ b $>$, e.g. <have $>$ f. $4 \mathrm{r}$, $<$ be-leve $>$ f. 5 r, <vnto $>$ f. 4 r. In initial position it has a long approach stroke, e.g. <vppon> f. $22 r$. In medial position there is another type of $\langle v\rangle$ which resembles the shape of the $<b>$. The left limb is at times slightly more oblique than that of the $<$ b>, e.g. <have> f. 19v. 


\begin{tabular}{|c|c|c|}
\hline & $\begin{array}{l}\text { Cambridge University Library } \\
\text { Kk.1.3 (part 11) }\end{array}$ & $\begin{array}{ll}\text { Oxford, Bodleian } & \text { Library } \\
\text { Hatton } 50 & \end{array}$ \\
\hline$\langle b\rangle$ & $\begin{array}{l}\text { Occurs in both initial and medial } \\
\text { position with the same shape, } \\
\text { e.g. <busy> f. } 4 \mathrm{v} \text {, < <habundaunce } \\
\text { f. } 4 \mathrm{r},<\text { be-leve }>\text { f. } 5 \text { r. }\end{array}$ & $\begin{array}{l}\text { Occurs in both initial and medial } \\
\text { position with the same shape, } \\
\text { e.g. <brothir }>\mathrm{f} .23 \mathrm{r} \text {, <abyde> f. } \\
\text { 22r. } \\
\text { In initial position a capitalised 'b' } \\
\text { is common in places where } \\
\text { present-day usage would not } \\
\text { require a capital, e.g. }<\text { Brothir }>\mathrm{f} \text {. } \\
\text { 23r, < Batellis }>\mathrm{f} \text {. } 23 \mathrm{r} \text {. }\end{array}$ \\
\hline
\end{tabular}

$<e>\quad$ In final position the scribe uses two types:

(1) A present-day-like one.

(2) A round 'e', e.g. <grave> f. 5r, $<$ brede $>$ f. 5 r, <done $>$ f. $7 \mathrm{v}$ and $<$ have $>$ f. 4r, <atte $>$ f. 9v, though the round 'e' occurs less often. In other positions the round ' $\mathrm{e}$ ' is rarely used but it occurs occasionally: e.g. $<$ Resoun $>$ f. 3 r.

In all positions the scribe uses a present-day-like 'e', e.g. <were> f. 23r, <euer> f. 21v. 


\begin{tabular}{|c|c|c|}
\hline & $\begin{array}{l}\text { Cambridge University Library } \\
\text { Kk.1.3 (part 11) }\end{array}$ & $\begin{array}{lll}\text { Oxford, } & \text { Bodleian } & \text { Library } \\
\text { Hatton } 50 & & \end{array}$ \\
\hline$\langle b\rangle$ & $\begin{array}{l}\text { Is shaped with a vertical stroke } \\
\text { with a very short lead-in or even } \\
\text { non-existent stroke for the left } \\
\text { arm, and a curved limb joined to } \\
\text { the left arm without leaving any } \\
\text { space, e.g. <pought>. } \\
\text { It occurs only in initial and final } \\
\text { position including abbreviated } \\
\text { words, and never in the middle of } \\
\text { a word. It is essentially used for } \\
\text { pronouns, prepositions and } \\
\text { conjunctions with the exception } \\
\text { of the lexical item <think> and } \\
\text { all its derived forms <thought>, } \\
<\text { thoughtful>, etc. which are } \\
\text { frequently spelled with 'p' rather } \\
\text { than 'th'. }\end{array}$ & $\begin{array}{l}\text { Is shaped with a vertical stroke } \\
\text { with a very short lead-in stroke } \\
\text { for the left arm and a curved limb } \\
\text { joined to the left arm without } \\
\text { leaving any space, e.g. }<p^{\mathrm{e}}>\text { f. } 24 \mathrm{r} \text {. } \\
\text { It occurs only in initial position } \\
\text { and mainly at the end of a line in } \\
\text { abbreviated words. It is primarily } \\
\text { used for the article 'the' and the } \\
\text { adverb 'there'. }\end{array}$ \\
\hline$\langle 3\rangle$ & $\begin{array}{l}\text { The head of the letter is angular } \\
\text { while its tail is curve. It is used in } \\
\text { three contexts: } \\
\text { (1) As an alternative for <gh>, } \\
\text { e.g. <nouzte }>\text { f. } 5 \mathrm{v} \text {. } \\
\text { (2) For the sound represented by } \\
\text { other scribes with the spelling } \\
<y>\text {, e.g. <3owe }>\mathrm{f} \text {. } 7 \mathrm{r},<3 \text { onge }>\mathrm{f} \text {. } \\
9 \mathrm{v} \text {. } \\
\text { (3) In words which seem to show } \\
\text { a palatalised consonant, e.g. } \\
<\text { azenste }>\mathrm{f} .5 \mathrm{v},<\mathrm{a} \text { eine }>\mathrm{f} \text {. } 5 \mathrm{r} \text {. } \\
\text { In later pages of this manuscript } \\
\text { the shape of the yogh changes } \\
\text { slightly and the tail curves up to } \\
\text { the right to join the following } \\
\text { letter, e.g. }<3 \text { it }>\mathrm{f} \text {. } 60 \mathrm{v} \text {. }\end{array}$ & $\begin{array}{l}\text { Both the head of the letter and } \\
\text { the tail are angular and the tail } \\
\text { curves up to the right to join the } \\
\text { following letter. It is used in } \\
\text { three contexts. } \\
\text { (1) As an alternative for <gh>, } \\
\text { e.g. <faw3te }>\text { f. } 23 \mathrm{r} \text {. } \\
\text { (2) For the sound represented by } \\
\text { other scribes with the spelling } \\
<y>\text {, e.g. <3ow }>\text { f. } 24 \mathrm{v} \text {, <3onge }> \\
\text { f. } 24 \mathrm{r} \text {. } \\
\text { (3) In words which seem to show } \\
\text { a palatalised consonant, e.g. } \\
<3^{\wedge} \mathrm{i}^{\wedge} \text { ftis }>\text { f. } 23 \mathrm{r},<\text { azenste }>\text { f. } \\
24 \mathrm{v},<\text {, azene }>\text { f. } 25 \mathrm{v} \text {. }\end{array}$ \\
\hline
\end{tabular}




\subsection{Comparison of words and letters in CULKk.1.3 (part 11) and Hatt50}

The above description of the letter forms in both manuscripts shows many similarities between the outputs of both texts. Comparison of letters in exactly the same contexts also shows that the final look of a word is, in many cases, almost identical. Most of the spellings selected coincide in the examples for both texts, although, as stated in Section 4 below, spellings are not always the same. Allowing for the fact that the scribe shows alternative shapes for some of the letters and that, as seen above, his repertoire is wider in CULKk.1.3, whenever the shapes coincide there are striking similarities which would suggest that both texts shared a common scribe. There are only a few features that are not alike, and this might be due to the degree of formality of the script that, as Mosser \& Mooney (2014) suggested, seems to be less formal in the copying of Hatt50. Examples of these are the formation of minims for letters $\langle\mathrm{m}\rangle,\langle\mathrm{n}\rangle$, and $<\mathrm{u}>$. In CULKk.1.3 these minims are mainly a neat vertical stroke lacking a connection to join them together and showing only a hair-line stroke. In the examples for ANY, EVER, MAKE, or THAN the minims for the letters $<\mathrm{n}>$, $<\mathrm{u}>$, and $<\mathrm{m}>$ in both texts are shown in Appendix 3. In Hatt50 and some examples of CULKk.1.3 the writing is executed more rapidly and the minims are joined with a connecting line from the bottom of the first minim to the top of the next one, as the pen is not lifted between the minims, so that the resulting letter closely resembles a modern shape as in the examples for MANY, MUCH, NOR, and NEVER. Another letter shape which differs clearly in both manuscripts is the yogh. The examples in Appendix 3 for YEAR (3eer) and IF (3if/3yf) show that in Hatt50 the tail curves up to the right to join the following letter. In CULKk.1.3 the tail is curve turning to the left with no connecting stroke. However, as the copying moves on along this manuscript the shape of the yogh becomes more like the one exhibited in Hatt50. In spite of these different letter shapes that seem to indicate in the case of Hatt50 a rapid script, from the rest of the evidence obtained from both texts I would agree with Mosser and Mooney that the same scribe was responsible for both works.

\section{Scribe's linguistic repertoires}

The aim of this section is to focus on the linguistic features of Hand B in Hatt50 and CULKk.1.3 (part 11). The language of both texts shows differences and similarities in the use of some common forms. A close comparison of these 
forms is carried out to determine the degree of consistency in the scribe's spelling system or if, on the contrary, the spelling in each case might have been determined by that of the exemplars the scribe is copying from. The type of text also might influence the scribe's choices. By comparing forms and features in both texts and by contrasting these features with other scribes' we aim at identifying possible copying layers.

\subsection{Purely orthographic conventions}

For the suffix '+able' and word-terminating sequences '+ple' and '+tle', our scribe has a tendency to use either of the medial vowels $\langle i>$ or $\langle y>$ instead of medial $<\mathrm{e}>$. In Hatt50 there is a high degree of consistency and only the cases for ' + tle' show variation (-till 14x and -tell 24x). In CULKk.1.3 (part 11) spellings with medial $<\mathrm{i}>$ or $<\mathrm{y}>$ in these sequences are more common than those with $<\mathrm{e}>$, although there are also cases with final $<$ e $>$, especially for ' + ble' (-bill $8 \mathrm{x}$, -ble $8 \mathrm{x})$, for ' + tle' (-til, 4x, -teyle 1x, -telle 1x). This manuscript also shows cases of $<+$ dell $>$ and $<+$ kill $>$ for endings '+dle' and '+kle'. These suffixes are also spelled with medial vowels $<\mathrm{i}\rangle$ or $\langle\mathrm{y}\rangle$ by the other two scribes in Hatt50. The Beryn Scribe uses essentially <+pill $>$ and $<+$ bill $>$ and, although there are also cases of $<+$ till $>/<+$ tyll $>$, the preferred form for ' + tle' is $<+$ tell $>$. Hand C shows the same preferences and he also has <+tell> as the preferred form for 'ttle'. The coincidences in the choices of the three scribes of Hatt50 could have an origin in the exemplar for the Brut Chronicle. There is no way to know whether the three scribes were using the same exemplar, although it seems that whatever text/s they were copying from it/they belonged to the same family of manuscripts. ${ }^{30}$ From a comparative analysis of these forms and features in the three scribes' productions, it seems likely that they shared the same exemplar given the many common features in their spellings. However, Hatt50 Hand B, when copying CULKk.1.3 (part 11), shares to some extent those features which might suggest that they are not only inherited from the exemplar but also part of the scribe's personal repertoire. The Beryn Scribe when copying CULKk.1.3 (part 10) also uses the same suffixes as those used when copying Hatt50. If all the three scribes involved in the copying of Hatt50 had a similar training or

\footnotetext{
${ }^{30}$ Matheson (1998) identifies different groups and families for all the manuscripts of the Brut Chronicle and Hatt50 is parallel to some others and grouped together with them into what he calls 'The abbreviated Version to 1419: Group B'.
} 
geographical origin this could be an explanation for the similarities in these spelling choices. ${ }^{31}$

For the sequences '+ace', '+ice', and '+ece' there is also a strong tendency to use $\langle\mathrm{s}\rangle$ instead of $\langle\mathrm{c}\rangle$. In the sample from Hatt50, there are $6 \mathrm{x}$ of words in which these sequences are found with $<\mathrm{s}>$ and $4 \mathrm{x}$ with $<\mathrm{c}>$, while CULKk.1.3 (part 11) has $14 \mathrm{x}$ with $<\mathrm{c}>$ and $9 \mathrm{x}$ with $<\mathrm{s}>$. It seems from this evidence that there is no significant preference for either of them, even if $\langle s\rangle$ has a slightly higher incidence. Comparison with the outputs of the other scribes in Hatt50 shows that the tendency to use $<\mathrm{s}>$ is higher in the sections copied by the Beryn Scribe, although he also uses $\langle\mathrm{c}\rangle$, while Hand $\mathrm{C}$ uses either $\langle\mathrm{s}\rangle$ or $\langle\mathrm{c}\rangle$ in equal proportions. When copying CULKk.1.3 (part 10), the Beryn Scribe tends to use $<\mathrm{c}>$ more often than $<\mathrm{s}>$. It is possible that the exemplar/s for the Brut Chronicle had this feature and that all the scribes involved in the copying had both forms in their personal repertoires, since using one or the other does not imply any phonological variation, being a matter of written convention.

For intervocalic $/ \mathrm{v} /$ in Hatt50 the commonest spelling for Hand $\mathrm{B}$ is $\langle\mathrm{v}\rangle$ $(50 \mathrm{x})$, being 83.3 per cent of the cases, as against $<\mathrm{u}>(10 \mathrm{x})$ with a percentage of usage of 16.6. This proportion gets inverted in words where there is an abbreviation of the syllable <ver $>$. In those cases, $<\mathrm{u}>$ is used in 86.9 per cent of the cases while the percentage of use of $\langle v\rangle$ is 13 per cent. The figures are similar in CULKk.1.3 (part 11) where $<\mathrm{v}>$ occurs in 68.9 per cent of the cases with eighty instances in the sample, and $<\mathrm{u}>$ occurs in 31 per cent of the cases on thirty-six occasions. Conversely, in abbreviated contexts $<\mathrm{u}>$ represents 77.2 per cent and $<v>22.7$ per cent. The other scribes in Hatt50 also follow the same convention of using $\langle\mathrm{v}\rangle$ rather than $\langle\mathrm{u}\rangle$, although the Beryn Scribe is more consistent than Hand $\mathrm{B}$ as he uses $<\mathrm{v}>$ in 100 per cent of the non-abbreviated occurrences, and Hand $\mathrm{C}$ in 95.5 per cent of the non-abbreviated syllables. The percentage of usage of $<\mathrm{v}\rangle$ in CULKk.1.3 (part 10) by the Beryn Scribe is very high as well $(93.4 \%)$. In the $15^{\text {th }}$ century using $<\mathrm{u}>$ for $/ \mathrm{v} /$ was commoner than using $<v>$. In this respect these three scribes seem to be following similar conventions. Although it is not impossible that working independently, and in different places, the three scribes could have shared this feature, it is more likely that it should come either from the copying of works where this was the ordinary practice or from having a similar training.

\footnotetext{
${ }^{31}$ Although there is no data in e-LALME for the geographical distribution of these suffixes.
} 
The plural of nouns has very similar outputs in both manuscripts, although the percentages are not identical. In Hatt 50 plural is marked by $<-$ is $>$ in 92 per cent of the plural nouns, while <-ys> represents only 6.5 per cent, and $<-s>1.4$ per cent. In CULKk.1.3 (part 11) the commonest suffix is also <-is> comprising 45 per cent of the endings, followed by <-ys $>$ with a 38.4 per cent. In this text $<-$ es $>$ occurs in certain words and it represents 12.1 per cent, and $<-$ s $>$ is the plural suffix in 4.3 per cent of the nouns. These endings are common and widely used by many scribes in the $15^{\text {th }}$ century.

The spelling for words that originally had postvocalic/x/varies considerably and this scribe has two main alternatives: <gh>, which represents 57.5 per cent of the instances $(61 \mathrm{x})$ in Hatt50 and 60.3 per cent (102x) in CULKk.1.3 (part $11)$; and $\langle 3\rangle$, which occurs in 31.1 per cent $(33 x)$ of the cases in Hatt50 and in 39.6 per cent (67x) in CULKk.1.3 (part 11). Besides, in Hatt50 there are eleven instances of $\langle\mathrm{h}\rangle$ and one of $\langle\mathrm{g}\rangle$. The usual practice for this feature in the other two scribes in Hatt50 differs from that of Hand B. The Beryn Scribe has a clear preference for $\langle 3\rangle$ and he uses it in all the instances. Hand $\mathrm{C}$ has a slight preference for $\langle$ gh $>$ over $<3>$. His percentage of usage is almost identical to that of Hand B (58.4\% of the cases are spelled with $<\mathrm{gh}>)$. The Beryn Scribe in CULKk.1.3 (part 10) also uses $<3>$ in 97.6 per cent of the cases, which might indicate that that spelling is the form he deployed from his own repertoire. The evidence suggests that for Hand $\mathrm{B}$, there is no unique way to portray the reflexes of post-vocalic $/ \mathrm{x} /$, and he seems to be comfortable with the forms he produces, whether they were originally in his exemplars or not.

There is also another spelling characteristic which is highly marked in Hatt50 but which occurs only sporadically in CULKk.1.3 (part 11). For the palatal fricative sound / $\int /$ in Hatt50 the scribe invariably uses $\langle$ sch $>(73 x)$, while in CULKk.1.3 (part 11) most of the time (77x) the spelling is $<\mathrm{sh}>$, with $<$ sch> occurring only $15 x$. This might suggest that in the exemplar from which he was copying the usual spelling was $<\mathrm{sh}>$, and that $<\mathrm{sch}>$ might have been a more spontaneous variant. The Beryn Scribe in the Hatt50 sample shows only one occurrence of $<\mathrm{sch}>$ against the 127 cases of $<\mathrm{sh}>$, and in CULKk.1.3 (part 10) there are no occurrences of this spelling at all. Conversely, Hand C in Hatt50 uses $<$ sch $>206$ times in the sample and $<$ sh $>$ only in eight words. For this feature, if the three scribes were copying from the same exemplar, they made different choices. If we apply the majority rule, we should conclude that the spelling for this sound in the exemplar would have been $<$ sch $>$, since two out of three copyists prefer that spelling. However, there is no way to be certain 
from the extant evidence, and one cannot draw a conclusion from this item in isolation.

\subsection{Possible phonological realisation with spelling variants}

Although it is not a majority feature in the texts, our scribe uses $\langle\mathrm{v}\rangle$ and $\langle\mathrm{W}\rangle$ indiscriminately in some words with $\mathrm{ME} / \mathrm{w} /$ : e.g. $<$ vyse $>/<$ wyse $>/<$ wise $>$ or $<$ vight $>$ / <wyght $>$ / <wight $>$ in CULKk.1.3 (part 11), and <Wortimere $>$ / $<$ Vortimere $>$ in Hatt50. Likewise, there is some instability in the use of $<w h>$ and $<\mathrm{w}>$ for $\mathrm{ME} / \mathrm{w} /$ or reflexes of $\mathrm{OE} / \mathrm{hw} /$ in both texts, since spellings such as <Whortegere $>$ alternate with $<$ Wortteger $>$ in Hatt50, and in CULKk.1.3 (part 11) $<$ where $>$ alternates with $<$ were $>$. The item WHAT is spelled $<$ wat $>9 x$ in Hatt50, and the spellings for WINE and WHITE are <whin $>$ and <wizte $>$ or $<$ wyhit $>$ respectively. The forms and spellings for $\mathrm{WHICH}$ in both texts are consistent. Hatt50 shows <wiche $>6 \mathrm{x}$, <wyche $>2 \mathrm{x}$, and $<$ the wyche $>1 \mathrm{x}$, while CULKk.1.3 (part 11) has <wiche $>25 x$, $<$ wich $>1 \mathrm{x}$, and $<$ wych $>1 \mathrm{x}$. The spelling for WHERE- shows some differences in both texts: in Hatt 50 <were-> occurs $8 \mathrm{x}$, and <where-> 7x. In CULKk.1.3 (part 11), on the contrary, there are no cases in the sample of $<$ were- $>$, only $<$ where- $>$ is to be found $(13 \mathrm{x})$. The item WHEN also shows variation but it is more stable in CULKk.1.3 (part 11), where only $<$ wh $>>$ forms occur. In Hatt50, however, there are several different forms: $<$ when $>33 \mathrm{x},<$ wen $>5 \mathrm{x},<$ whan $>4 \mathrm{x},<$ wan $>3 \mathrm{x},<$ when $>1 \mathrm{x}$, and $<$ whan $>1 \mathrm{x}$. This manuscript also attests several forms for the past plural of $\mathrm{BE}$ including $<$ where $>$. The past singular is mostly $<$ was $>$, but there is one instance of $<$ whas $>$. For the item WHILE there are also some alternative spellings such as <wyle $>$ $2 \mathrm{x},<$ while $>1 \mathrm{x}$, and $<$ wylis $>1 \mathrm{x}$. All this evidence suggests lack of aspiration in the sequence $<w h>$ in most words, and lack of the bilabial sound in words like $<$ holsom> (WHOLESOME). In the words found in the samples both features were very widespread in the $15^{\text {th }}$ century and the possible pronunciation that these spellings imply were the ones that eventually became standardised. They are not helpful for identifying the scribe's provenance. The other scribes of Hatt50 do not evidence this feature to the same extent as Hand B. The Beryn Scribe only tends to spell certain words with $<v>$, for example $<$ vomman $>$ for WOMAN, and when copying CULKk.1.3 (part 10) there is also a case of $<$ vombe $>$ for WOMB, while the rest of the words with initial /w/ are always spelled with $<\mathrm{w}>$. For Hand $\mathrm{C}$ in the Hatt50 sample, only one instance of this feature has been found, and the evidence is very weak, since it is a proper name $(<$ Wortigere $>$ for $<$ Vortigere $>$ ) and for names the scribes' behaviour could be 
disparate; if that was the form he encountered in his exemplar, it is likely that he decided not to change it, even if he had a more stable system for this feature than Hand B.

Instability of $/ \mathrm{h} /$. The scribe's spelling in both texts suggests that he might have been an $/ \mathrm{h} /$ dropper. There are alternative spellings for words with initial 'h', e.g. omage (HOMAGE) and abite (HABIT) in Hatt50, and eresie (HERESY), ole (HOLE), abit (HABIT) in CULKk.1.3 (part 11). There are also cases of unetymological $<\mathrm{h}>$ such as his or bys (IS) and botbir (OTHER) in Hatt50, and dishobey (DISOBEY) and bis (IS) in CULKk.1.3 (part 11). As for the other two scribes of Hatt50, only Hand $\mathrm{C}$ shows a similar instability in his production. It might be, then, that since Hand B shows a similar pattern of 'h' / non-'h' usage in both his texts, it was not inherited from his exemplar but was part of his linguistic spontaneous repertoire to the same extent shared with Hand C.

\subsection{Spelling of common words}

Some common words, such as AGAINST, AT, MANY, and UPON share spellings in both texts. AGAINST is invariably <azenste $>$. The preposition AT has a majority form <att $>$ in both texts. MANY occurs mainly as <many>, but in CULKk.1.3 (part 11) there are also 4x of <manyes. For the preposition UPON the scribe uses <vppon> 9x in Hatt50 and 4x in CULKk.1.3 (part 11). However, in both texts the form <oppon> occurs $4 \mathrm{x}$ and $1 \mathrm{x}$ respectively.

In spite of this apparent consistency, there are many other common words which differ in their spelling between the manuscripts. IF, for example, has three forms in Hatt50: <3yf $>4 \mathrm{x},<3$ if $>2 \mathrm{x},<\mathrm{yf}>1 \mathrm{x}$, while in CULKk.1.3 (part 11) there are seven different spelling variants: $<$ jff $>11 x,<$ if $>10 x,<3 y f>6 x,<$ iff $>$ $4 \mathrm{x},<3$ if $>4 \mathrm{x},<3 \mathrm{yff}>1 \mathrm{x},<\mathrm{iffe}>1 \mathrm{x}$. The commonest in this manuscript is $<\mathrm{jff}>$, which occurs frequently due to the layout of the text. This form tends to appear at the beginning of the line where the $<j>$ stands for a capital 'I'. The majority form <3yf $>$ in Hatt50 is shared by Hand C, which might suggest that they both had it in their exemplar/s (<3if $>$ could be easily included in the same group). Most of the variants in CULKk.1.3 (part 11) are probably dependent on the exemplar, but they can be found extensively in the $15^{\text {th }}$ century coexisting with what seems to be the scribe's majority forms.

There are other items whose occurrence seems to provide contradictory dialectal information about the scribe. The forms used for AGAIN are disparate in both texts. Hatt50 shows: <agayne $>10 x$, <azene $>3 x$, and $<a-3 e n e>1 x$, while in CULKk.1.3 (part 11) the forms <azein $>2 \mathrm{x}$ and $<$ azeine $>1 \mathrm{x}$ are found. The 
distributions for these forms in e-LALME do not always coincide in any particular place, since there is no single LP for any text in which a scribe uses all these forms, nor are these forms used in different LPs localised in the same place. However, if we move beyond the particular forms the scribe uses, and we classify them into more general types, the areas in which they could coexist are essentially in the eastern part of the country. ${ }^{32}$ The other Hatt50 scribes' data for this item are not very informative, nor do they provide a clear explanation for Hand B's behaviour regarding this item. The Beryn Scribe uses only <ageyn> (7x) here and in CULKk.1.3 (part 10) he is also consistent with this same form. Hand $\mathrm{C}$ has as a majority form <azene> (17x), which is a minority form for Hand $\mathrm{B}$, while his minority forms are <ageyne> $(1 \mathrm{x})$ and <agayne $>(1 \mathrm{x})$. It is difficult to figure out in this case what forms were in the exemplar/s and which ones are the product of spontaneous input. What seems to be clear is that our scribe lacks a coherent set of variants since his choices do not exhibit any geographical pattern.

The scribe displays two forms for ANY (<ony> $3 \mathrm{x}$, <any> $1 \mathrm{x})$ in Hatt50 and only one (<any> 9x) in CULKk.1.3 (part 11). <any> is widespread in the $15^{\text {th }}$ century and is the form that will eventually become standard; <ony> occurs also over a wide area. It seems plausible that any preference for either of them was dependent on what a scribe found in his copy-text. The preferred form for the Beryn Scribe both in Hatt50 and CULKk.1.3 (part 10) is <eny>, while Hand C has <ony> $3 \mathrm{x}$ and <eny> $1 \mathrm{x}$. Again, Hand $\mathrm{B}$ and Hand $\mathrm{C}$ seem to share the majority form that could have been that of the exemplar/s.

For BEFORE there are also four variants in both texts: <to-fore $>12 \mathrm{x}$, $<$ be-fore $>1 \mathrm{x},<$ afore $>1 \mathrm{x}$ in Hatt50, and <beforne $>1 \mathrm{x}$ in CULKk.1.3. The latter (form with-n-) is mainly found in texts localised in Norfolk, Ely, Suffolk, Essex, and occasionally in Lincolnshire (3 LPs), Sussex (3 LPs), Cambridgeshire (3 LPs), Northamptonshire (2 LPs), Nottinghamshire, Leicestershire, London, Bedfordshire, Berkshire, Buckinghamshire, and Kent (one LP in each of these counties). ${ }^{33}$ Forms with the prefix 'to-' are common in the South and Midlands, ${ }^{34}$ and those with 'a-' prefix and $<$ be-fore $>$ are scattered all over the

\footnotetext{
${ }^{32}$ See e-LALME DM, AGAIN: 'forms with -g- (a-gayne, ageyn, etc.)'; DM, AGAIN: 'forms with -3- (a-zayne, azein, etc.)'; DM, AGAIN: 'medial -ai- or -ay- (a-gaine, a-yayn, etc)'; DM, AGAIN: 'medial -ei- or -ey- (agein, a-yeyn, ozeine, etc.)'.

${ }^{33}$ See e-LALME DM, BEFORE adv/pr: '(-)forn(e)' type.

${ }^{34}$ See e-LALME DM, BEFORE adv/pr: 'forms with to-prefix'.
} 
country. ${ }^{35}$ If there were more occurrences of <beforne> in the part of the text beyond the sample, it would be a useful indicator for the scribe's provenance. A single occurrence is very weak evidence to come to any conclusions, especially when the forms he uses in Hatt50 are far more widespread.

The preferred form for MUCH in Hatt50 is <moche> 33x. The remainder are minority occurrences, with $4 \mathrm{x}<$ miche $>$ and three forms occurring only once (<muche>, <myche $>$, <mykyll $>$ ). The majority form in this manuscript is common in all the Midlands and South of the country. ${ }^{36}<$ miche> is less common and tends to occur more frequently in the Central and West Midlands. while <myche> seems to be more widely spread into the East Midlands. ${ }^{37}$ $<$ mykyll>, on the other hand, has a more northern distribution, although there are occurrences in the East Midlands as well. ${ }^{38}$ In the sample in CULKk.1.3 (part 11) there are only two instances of <muche>, which tends to have a denser occurrence in the West Midlands, although it occurs sporadically in the South and in East Anglia. ${ }^{39}$ The Beryn Scribe consistently uses <much>, both in Hatt50 and CULKk.1.3 (part 10). Hand C, on the contrary, exhibits four forms: $<$ muche $>17 \mathrm{x},<$ moche $>13 \mathrm{x},<$ much $>2 \mathrm{x}$, and $<$ mychill $>1 \mathrm{x}$. It is not clear what form could have been in the exemplar/s or if there was only one form or several. In any case, it seems that Hand B's attitude towards this item is flexible and that the forms he uses might have belonged to his passive or active repertoires.

The majority form for CHURCH in both manuscripts is <chirch>, commonly found in texts localised throughout the Midlands and South. ${ }^{40}$ There are also two forms which occur once: <church> in CULKk.1.3 (part 11) and $<$ cherch $>$ in Hatt50. Since these occur only once in different manuscripts, they both might have been relics present in the scribe's copy-text, or one of them could be a relic and the other a form from the scribe's spontaneous usage. Hand $\mathrm{C}$ in Hatt50 also has <chirch> once, and in the Beryn Scribe section there are

\footnotetext{
${ }^{35}$ See e-LALME DM, BEFORE adv/pr: 'forms with $a$-prefix'; DM, BEFORE adv/pr: 'forms with be-prefix'.

${ }^{36}$ See e-LALME DM, MUCH: 'moch' and 'mochel' types, all variants.

${ }^{37}$ See e-LALME DM, MUCH: 'mich' and 'michel' types, all variants. The specific forms $<$ miche $>$ and $<$ myche $>$ are part of the distribution shown on this DM. The distribution of any single form can be discovered using e-LALME's 'User-defined Maps'.

${ }^{38}$ See e-LALME DM, MUCH: 'mikel' type, all variants; DM MUCH: forms ending in -ill(e) or $-y l l(e)$.

${ }^{39}$ See e-LALME DM, MUCH: 'much' and 'muchel' types, all variants.

${ }^{40}$ See e-LALME DM, CHURCH: 'chir-' and 'chyr-' types.
} 
no occurrences of CHURCH, although in his copy of CULKk.1.3 (part 10) the form is also <chirch>.

The evidence for the item DEATH is difficult to interpret. The word appears invariably as <dehet $>14 \mathrm{x}$ in Hatt50, while in CULKk.1.3 (part 11) three forms are found: $<$ deith $>4 \mathrm{x},<$ deth $>3 \mathrm{x}$, and $<$ dede $>1 \mathrm{x}$. This word is an item for the LALME northern questionnaire so there is no evidence for the Southern part of the country. In any case, the spelling found in Hatt50 is not recorded at all. $<$ deth $>$ is widespread everywhere in the Midlands $;{ }^{41}<$ dede $>$ is very common in the Eastern part of the country; $;^{42}$ and forms with <ith> or <yth> occur sporadically in the North Midlands. ${ }^{43}$ Hand $\mathrm{C}$ in Hatt50 has <dehit> 7x and $<$ dehyt $>1 \mathrm{x}$. The Beryn Scribe offers no evidence for DEATH in this manuscript. As the forms found in Hatt50 are very uncommon and remarkably similar in the outputs of both scribes, it is reasonable to infer that they must have come down from a similar form in the exemplar/s.

Two forms for FIRE are found: <fere> in Hatt50 and <fier> in CULKk.1.3 (part 11). There are only two instances of this item in both manuscripts and, consequently, it is hard to say which form would be the scribe's spontaneous one, or whether it was one of these two. They have different dialectal distributions in e-LALME, but they coincide in Norfolk, Suffolk, Essex, and South Lincolnshire, ${ }^{44}$ so it would be perfectly possible for a single scribe to produce both of them. Hand C's forms are <fire $>$ and $<$ feir $>$, which do not coincide with any of the forms of Hand B, so if they were copying from the same exemplar, either one or both of them was altering the forms of the original text.

Hand B in Hatt50 only has one instance of the item SUCH and the form is very unusual: <schoche> $1 \mathrm{x}$. This form has been attested only once in $\mathrm{e}$ LALME, in an LP localised in Devon. ${ }^{45}$ In CULKk.1.3, on the contrary, there are many occurrences of this item and three variants are found: <suche $>21 \mathrm{x}$, $<$ such $>2 \mathrm{x}$, and $<$ shuche $>2 \mathrm{x}$. The first two are common in all areas in the South and Midlands; ${ }^{46}<$ shuche>, on the other hand, has been attested only in three

\footnotetext{
${ }^{41}$ See e-LALME DM, DEATH: 'deth' type.

${ }^{42}$ See e-LALME DM, DEATH: 'ded(-)' type.

${ }^{43}$ See e-LALME 'User-defined Maps': DEATH as 'deith', 'deithe', 'deip', 'deyth', 'deythe', and 'deyp'.

${ }^{44}$ See e-LALME DM, FIRE: 'fe(e)r' type, incl $v$-forms; FIRE: 'fier' and 'fyer' types.

${ }^{45}$ See LP 5030.

${ }^{46}$ See e-LALME 'User-defined Maps': SUCH as 'suche', 'such'.
} 
LPs in those same areas. ${ }^{47}$ The Beryn Scribe in Hatt50 only has the form $<$ such $>$ $2 \mathrm{x}$, and Hand $\mathrm{C}$ has a preferred form <schuche $>4 \mathrm{x}$, which is also uncommon, and then <scuche> $1 \mathrm{x}$ (which could be an error) and <suche> 1x. Hand C's majority form is close enough to Hand B's unique form to envisage a common origin as the possible explanation for the disparity in the forms exhibited by Hand $\mathrm{B}$ in his two productions. However, the minority form <shuche> in CULKk.1.3 might point to the fact that, if it is not the most spontaneous form, at least forms with palatalised initial consonants for SUCH could be part of the scribe's repertoire. The distributions of these forms in e-LALME do not provide useful information about the possible origin of the scribe, since their distribution is scattered throughout the South and Midlands.

\subsection{Morphological variants \\ 4.4.1 Pronouns and determiners}

The pronouns YE/YOU are complex as they are used with 2nd person singular and plural referents and both for nominative and oblique cases. Hatt50 Hand B's evidence shows that for the subject (both singular and plural) the only form used is $<3 e>19 x$, and for the object (singular and plural) $<30 w>18 x$. These forms basically coincide with those used by Hand $\mathrm{C}\langle 3 \mathrm{e}\rangle$, $<3$ ee $>/<30 w>$, $<$ zowe $>$, but differ from those in the Beryn Scribe section: <yee $>$ / <3ew $>$, $<$ zewe $>$. CULKk.1.3 (part 11) shows more variants, although the majority forms coincide with those of Hatt50 Hand B. For the nominative case there are $14 \mathrm{x}$ of $<3 \mathrm{e}>$ and $2 \mathrm{x}$ of $<\mathrm{you}>$, with the latter used as a singular form, while the former is found for both singular and plural. The oblique forms are $<30 w>6 x$, $<$ 3owe $>5 \mathrm{x}$, and $<30 u>1 \mathrm{x}$, the last being used only for the singular, and the other two for both singular and plural. The majority form in both texts for the nominative is not uncommon, while the minority one, $<$ you $>$, is very rare as subject. ${ }^{48}$ The object forms <3ow> and <3ou $>$ are densely spread in the Midlands. while <3owe $>$ is more infrequent but widely spread in the central Midlands. ${ }^{49}$

For the 2nd singular THOU, Hatt50 has <thow $>3 \mathrm{x}$, while CULKk.1.3 (part 11) has a variety of forms. The majority one is $<$ thow $>19 x$, also used by Hand $\mathrm{B}$ in Hatt50. In addition, the following forms occur: <thou $>14 \mathrm{x},<$ pou $>9 \mathrm{x}$,

\footnotetext{
${ }^{47}$ LP 313, LP 704, and LP 5040.

${ }^{48}$ See e-LALME DM, YE: 3 - forms and 'User-defined Maps': YE as 'yow'.

${ }^{49}$ See e-LALME 'User-defined Maps': YOU as 'zou', 'yow', and 'zowe'.
} 
$<$ thowe $>4 \mathrm{x},<$ pow $>1 \mathrm{x}$, and $<$ pu $>1 \mathrm{x}$. For the object pronoun THEE the only attestations are in CULKk.1.3 (part 11): <the $>31 \mathrm{x}$ and $<$ pe $>3 \mathrm{x}$. The scribe is more consistent in Hatt50, perhaps because his exemplar had few occurrences, while that for CULKk.1.3 (part 11) might have presented more variation which conformed to the scribe's own preferred usage. Hand C in Hatt50 consistently has $<$ thow $>$.

The forms for YOUR both in the singular and the plural are broadly consistent in both texts. The preferred form is <3owre>, but <3oure> also occurs. The percentages of use in both texts are very similar: <3owre $>$ is used in around 75 per cent and <3oure> in 25 per cent of all the occurrences of YOUR in the two manuscripts. THY/THYNE do not show significant differences, except that attestations in Hatt50 are few. Conversely, in CULKk.1.3, and due to the nature and inner structure of poem, with a speaker addressing directly his son, the number of occurrences of this item as pronoun or determiner is much higher. The preferred form in both manuscripts is $<$ thi $>$, although CULKk.1.3 (part 11) also has instances of $<$ thy $>12 \mathrm{x}$ and $<$ thyne $>1 \mathrm{x}$.

The use of alternative forms for the neuter pronoun IT, either as subject or as object, differs considerably in both texts. The sample for Hand B in Hatt50 shows forms with initial 'h' only: <hit $>26 \mathrm{x}$ and $<$ hyt $>4 \mathrm{x}$. In CULKk.1.3 (part 11) the majority of the forms have no initial ' $h$ ': $<$ it $>62 x,<$ hit $>8 x,<$ hyt $>2 x$, $<y t>1 x$, and $<\mathrm{itt}>1 \mathrm{x}$. Hand $\mathrm{C}$ in Hatt50 also shows a preference for ' $h$ ' forms: $<$ hit $>19 x,<$ hyt $>1,<i t>2 x$, and $<y t>1 x$. The Beryn Scribe, on the other hand, has invariably $<i t>25 x$. From the dialectal point of view, the use of these different types is relevant, although the 'h'-less variant was spreading throughout the country in the $15^{\text {th }}$ century..$^{50}$ Forms with ' $h$ ' are also common, although they do not seem to occur so frequently in the North or Eastern areas. ${ }^{51}$ The differences in CULKk.1.3 (part 11) might be due to the scribe's attempt to be faithful to his copy-text, <it>. Nevertheless, he occasionally introduces the form with initial ' $h$ ' (10x), which perhaps was his own usage.

Six alternative forms are found for THEIR in Hatt50: $<$ here $>6 \mathrm{x},<$ her $>5 \mathrm{x}$, $<$ hir $>5 \mathrm{x},<$ theyre $>3 \mathrm{x},<$ hire $>1 \mathrm{x}$, and $<$ their $>1 \mathrm{x}$; and three in CULKk.1.3 (part 11): $<$ her $>11 \mathrm{x},<$ hir $>5 \mathrm{x}$, and $<$ here $>2 \mathrm{x}$. Among these forms the ones with a more limited geographical occurrence are $<$ hir $>$ and $<$ hire $>$, which are mainly used in the South Midlands and South. ${ }^{52}$

\footnotetext{
${ }^{50}$ See e-LALME DM, IT: spellings without initial ' $h$-'.

${ }^{51}$ See e-LALME DM, IT: 'h-' type, all variants.

${ }^{52}$ See e-LALME DM, THEIR: 'hir' type, simple $i$ or $y$ as medial vowel.
} 
The majority form for THEM in both texts is $\langle$ hem $>, 60 \mathrm{x}$ in Hatt50 and $12 \mathrm{x}$ in CULKk.1.3 (part 11), with abbreviated forms such as $<$ he $m>2 \mathrm{x}$ in Hatt50 and 1x in CULKk.1.3 (part 11). This manuscript also shows one case of $<$ heme>. 'th-' type forms are found in Hatt50 only: <them>10x, <theme> 1x. These are less common than the ' $h$-' forms but they were widespread in the $15^{\text {th }}$ century. ${ }^{53}$ Hand C in Hatt50 also has some cases of 'th-' forms, <they> 4x, although his majority form is $<$ hem $>49 x$.

The evidence in both texts for the plural nominative pronoun THEY is consistent. Both have <they> as the majority form, although there are many more occurrences in Hatt50 (86x). CULKk.1.3 (part 11) has <they> 24x and $<$ pey> 2x. <thei> occurs once in Hatt50 and <pay> once in CULKk.1.3 (part 11). None of these forms are dialectally interesting since they are common and scattered across the whole country.

\subsubsection{Verbs}

The narrative of Hatt50 does not allow for many verbs in the present as the topic is a historical chronicle, and so most of the verbs are in the past. However, there are four singular forms in the sample analysed with the endings $<-h i t>2 x$, $<-\mathrm{ht}>1 \mathrm{x}$, and $<-\mathrm{jt}>1 \mathrm{x}$. In the plural there are nine cases ending in $<-\mathrm{in}>3 \mathrm{x}$, $<\emptyset>2 \mathrm{x},<-\mathrm{yn}>1 \mathrm{x},<-$ ine $>1 \mathrm{x},<-$ en $>1 \mathrm{x}$, and $<-$ it $>1 \mathrm{x}$. CULKk.1.3, on the other hand, has many forms in the present tense both for the singular and the plural. The endings for the singular are: $<-$ ith $>59 x,<-$ eth $>11 x,<-y t h>9 x,<\varnothing>6 x$, $<-$ ithe $>4 \mathrm{x},<-\mathrm{th}>1 \mathrm{x}$, and $<-\mathrm{t}>1 \mathrm{x}$. The plural endings are: $<-$ en $>13 \mathrm{x},<\varnothing>13 \mathrm{x}$, $<-y n>4 x,<-n>2 x$, and $<-n e>1 x$. The forms for the singular differ considerably in both manuscripts. Hand $\mathrm{C}$ in Hatt50 exhibits very similar endings to those of Hand $B,<-i t>4 x$, and <-hit $>3 x$, which might suggest that these were endings found in the exemplar. The Beryn Scribe differs again here and shows commoner endings for this feature: $<-$ ith $>6 x,<-y t h>3 x$. e-LALME does not provide complete geographical coverage for present tense endings. Some of the singular forms found in Hatt50 (Hand B and Hand C) are not widely spread and they are most apparent in Norfolk in the e-LALME sources. ${ }^{54}$ Those in CULKk.1.3 (part 11) are very common forms in the Midlands and South. The plural endings in both cases are typical of the Midlands.

\footnotetext{
${ }^{53}$ See e-LALME DM, THEM: 'th-' type, all variants.

${ }^{54}$ See e-LALME 'User-defined Maps': 3sg pres ind ending as '-ht', '-eht', and '-iht'.
} 
There is consistency in the forms used in both texts for ARE. Both use $<$ bene $>$, <ben $>$, and $<$ be $>$, although there is one instance of $<$ bein $>$, occurring only in CULKk.1.3 (part 11). In e-LALME < bein> occurs in 13 LPs, most in Essex or nearby, although it occurs in two LPs in Norfolk, two in Cheshire, and one in Lancashire. ${ }^{55}$ The scribe's single occurrence might well have been carried over from the exemplar while still familiar to the scribe.

The number of occurrences of verbs in the past is much higher in Hatt50 than in CULKk.1.3 due to the nature of the narrative as mentioned above. The endings for the weak past are similar in both manuscripts with a few exceptions. Hatt50's commonest ending are $<-\mathrm{id}>78 \mathrm{x}$ or $<-\mathrm{yd}>35 \mathrm{x}$. Less common endings are: $<-$ it $>5 \mathrm{x},<-$ ed $>4 \mathrm{x},<-$ de $>4 \mathrm{x},<-\mathrm{iid}>2 \mathrm{x},<-\mathrm{yt}>1 \mathrm{x},<-\mathrm{t}>1 \mathrm{x},<-\mathrm{d}>1 \mathrm{x}$, and $<-$ te $>1 \mathrm{x}$. In CULKk.1.3 (part 11) the most used endings are also $<-$ id $>22 \mathrm{x}$ or $<-y d>8 x$. Minor endings are $<-$ ed $>5 x,<-d>1 x$, and $<-d e>1 x$. The comparison with the endings employed by the other two scribes in Hatt50 is crucial here to understand our scribe's behaviour. The Beryn Scribe uses $<-\mathrm{id}>38 \mathrm{x}$, <-ed $>4 \mathrm{x}$, $<-\mathrm{it}>3 \mathrm{x}$, and $<-\mathrm{d}>1 \mathrm{x}$. In turn, Hand $\mathrm{C}$ uses $<-\mathrm{yd}>55 \mathrm{x},<-\mathrm{id}>41 \mathrm{x},<-\mathrm{it}>12 \mathrm{x}$, $<-$ de $>12 x$, and $<-$ ed $>5 x$. The Beryn Scribe's practice is highly systematic in this respect. ${ }^{56}$ The form of the verbal ending depends on the final consonant in the stem: <-it> is used when the final consonants in the verbal forms are ' $d$ ', ' $g$ ', or the sequences 'ng', 'bl', or 'dr'; <-ed $>$ is used after a nasal and occasionally after ' $\mathrm{t}$ ', 's', and ' $\mathrm{x}$ '; $<-\mathrm{id}>$ and the alternative $<-y d>$ are used after any other consonant and only rarely after a vowel; <-d> is used after a vowel, 'i' / 'y' or 'u' / 'w'. Hand $C$ follows a similar system but slightly more relaxed. This scribe uses $<$ it $>$ when the final consonants in the verbal forms are 'd', 'g'; <-ed $>$ is used after a vowel or 'th'; <-id $>$ and the alternative $<-y d>$ are used after any other consonant and only rarely after a vowel. Hand B uses the same endings and similar distributions, although not identical since <-it> is used after 'd', 'g', and also occasionally after 'l' but not in all the instances of verbs with these endings. $<-\mathrm{id}>$ and $<-\mathrm{yd}>$ are used after most consonants although there are not any examples of <-yd $>$ after ' $b$ ' or ' $t$ '. $<-$-ed $>$ or $<-$ de $>$ are occasionally used after a vowel and $<-\mathrm{d}>$ after ' $\mathrm{n}$ ' or ' $\mathrm{g}$ '. Hand $\mathrm{B}$ does not show the same degree of systematisation as found in the section copied by the Beryn Scribe or even in that by Hand C. Since in CULKk.1.3 (part 11) the evidence seems to be different, having no $<-$ it $>$ endings, it could be inferred that Hand B is following

\footnotetext{
${ }^{55}$ See e-LALME 'User-defined Maps': ARE as 'bein'.

${ }^{56}$ See Carrillo-Linares \& Williamson (2020).
} 
loosely what he might have had in his exemplar, and the same could be said for his copy of CULKk.1.3 (part 11).

Regarding the non-personal forms of the verbs, none of the 149 past participles in Hatt50 have a prefix, while in CULKk.1.3 (part 11) there are seven participles (out of 108) with the prefix ' $\mathrm{j}$-'. The use of the prefix in this text might have been exemplar-induced. Comparison with other manuscripts of the same work shows that they were used in the same contexts, so it seems that in this respect the scribe was just being faithful to what he had in his source. The weak past participle endings follow the same pattern as the weak preterite forms in both manuscripts and the conclusions we reach should be the same. Hatt50's endings are: $<-\mathrm{id}>37 \mathrm{x},<-\mathrm{yd}>27 \mathrm{x}$ as majority forms, and $<-\mathrm{it}>3 \mathrm{x},<-\mathrm{d}>1 \mathrm{x}$, $<-$ de $>1 \mathrm{x},<-\mathrm{ijd}>1 \mathrm{x}$, and $<-$ te $>1 \mathrm{x}$ comprising just a few occurrences. In CULKk.1.3 (part 11) the endings are identical to those of the weak preterite: $<-$ id $>27 x,<-y d>13 x,<-e d>14 x,<-d>2 x,<-d e>1 x$. As for the infinitive endings, in the Hatt50 sample there are 235 infinitives and only three instances of infinitive ending ( $<$ done $>2 \mathrm{x}$ and $<$ begotten $>1 \mathrm{x})$. A few more cases occur in CULKk.1.3 (part 11) since there are 231 infinitive forms and fourteen of them have an ending $(<$ ben $>2 \mathrm{x},<$ done $>2 \mathrm{x},<$ herken $>2 \mathrm{x},<$ gan $>1 \mathrm{x},<$ stinkin $>1 \mathrm{x}$, $<$ twynnen $>1 \mathrm{x}$, <stonden $>1 \mathrm{x}$, <vsen $>1 \mathrm{x}$, < followen $>1 \mathrm{x},<$ praien $>1 \mathrm{x}$, and $<$ hoppyn $>1 \mathrm{x}$ ). It seems again that the scribe might be following the forms in his exemplars and that adding an infinitive ending is not a spontaneous choice in his copying practice.

4.5 Forms without occurrences in one of the manuscripts but comparable to the other Hatt50 scribes

As for the items DOES / GOES, Hatt50 Hand B does not have verbs in the 3rd person singular, while CULKk.1.3 (part 11) exhibits the forms $<$ doith $>5 x$, $<$ dooith $>1 \mathrm{x}$, < doeth $>1 \mathrm{x},<$ gooith $>2 \mathrm{x}$, < goith $>1 \mathrm{x},<$ goo $>1 \mathrm{x}$. e-LALME data for 3rd person singular present indicative ending in $<-$ ith $>$ indicates that the suffix is spread throughout the Midlands and South, ${ }^{57}$ though with verbs ending in $<0>$ the commonest ending seems to be $<-$ th $>$ (without a vowel). The records for DOES and GOES with <-ith> are not many but, at the same time, they are not localised in a small or compact area. ${ }^{58}$ On the contrary, the evidence is

\footnotetext{
${ }^{57}$ See e-LALME DM, 3sg pres ind: '-ith' and '-yth' types.

${ }^{58}$ See e-LALME 'User-defined Maps': DOES as 'doith', 'doyth', 'doip', 'doythe', and 'doyp'; GOES as 'goith', 'goithe', 'goyth', 'goip', 'goythe', and 'goyp'.
} 
scattered throughout the South Midlands and South of the country. Hand C does not exhibit a similar form, since the only occurrence is <goohit>; the Beryn Scribe does not have any instances for this word in Hatt50, but in the Life of Our Lady in CULKk.1.3 (part 10) there are four occurrences of $<$ goith $>.^{59}$

A similar spelling is found for the item BOTH in CULKk.1.3 (part 11): $<$ boith $>2 \mathrm{x}$, <bothe $>1 \mathrm{x}$. As for the previous item, there is no evidence in the sample in Hatt50. e-LALME data indicate that the spelling <boith> is uncommon (found in $13 \mathrm{LPs}$ ) but, as for $<$ goith $>$ and $<$ doith $>$, the occurrences are localised in the North, the Midlands, and the South.$^{60}$ Neither the Beryn Scribe nor any of the other scribes contributing to the copying of the Brut Chronicle use this peculiar form. It is impossible to decide in this case if it was a natural choice of form for this item or if he was just reflecting his copy-text.

The compounds THE ONE and THE OTHER do not occur in CULKk.1.3 (part 11). The former occurs $4 \mathrm{x}$ in the Hatt50 sample as $<$ the tone $>$. The same form is used by Hand $\mathrm{C}$ in Hatt50, and the Beryn Scribe uses <the toon $>3 \mathrm{x}$ and $<$ pe toon $>1 \mathrm{x}$. The majority form for THE OTHER occurs in the Hand $\mathrm{B}$ sample of Hatt50 as <the tothir $>3 \mathrm{x}$, and there is also one case of $<$ pe tothir $>$. Hand C's forms are $<$ the tothir $>1 \mathrm{x},<$ pe tothir $>1 \mathrm{x},<$ the todir $>1 \mathrm{x},<$ tothir $>1$; the Beryn Scribe has $<$ the todir $>4 \mathrm{x}$. It is not possible to localise the occurrences of these items since the distributions supplied by e-LALME are diffuse. Since these forms are not common and not restricted to any particular area, the exemplar from which these scribes were copying may have had something very similar to their actual outputs for this item, and so the three scribes preserved these forms in their copies.

\subsection{Forms with abbreviations}

In general, the number of abbreviations is higher in Hatt50 than in CULKk.1.3 (part 11), but the sequences of letters abbreviated are similar: 'e' and ' $n$ ' are the commonest letters abbreviated, but 'er', 'us', 'ir', 'ro', 'e', 'i', 'm', or 'r' are also

\footnotetext{
59 The Beryn Scribe also produces these forms in The Canterbury Tales preserved in Northumberland, Alnwick Castle 455 and in Princeton, Firestone Library 100, as well as in the copy of Prick of Conscience in Oxford, St John's College 57. Other scribes copying the Brut Chronicle along with the Beryn Scribe in Oxford, Bodleian Library, Tanner 11 and Ann Arbor, University of Michigan, Hatcher Library, 225 also exhibit these forms.

${ }^{60}$ See e-LALME 'User-defined Maps': BOTH as 'boith', 'boip', and 'boithe'.
} 
subject to abbreviation. There are some words that occur frequently in both texts and that might show abbreviated syllables or suspended letters. It is worth noting that the way they are spelled or the type of abbreviation used is not always the same in both texts. As an example, the forms for the items THEN and WHEN show variation both in the vowels, where there is an alternation between $\langle\mathrm{a}\rangle$ and $\langle\mathrm{e}\rangle$, and also in the way they can be abbreviated. For THEN, Hatt50's sample has four choices: $<$ then $>31 \mathrm{x},<$ than $>12 \mathrm{x},<$ thane $>1 \mathrm{x}$, and $<$ then $>1 \mathrm{x}$. The last form is abbreviated with suspension of the nasal sound and it happens only once. The choices found in CULKk.1.3 are slightly different: the majority form is abbreviated, <than $n e>6 \mathrm{x}$, and the rest of the occurrences are $<$ thane $>3 \mathrm{x}$ and $<$ than $>1 \mathrm{x}$. There are no forms with medial $<\mathrm{e}>$, which is the commonest in Hatt50. Regarding WHEN, the preferred form in Hatt50 is $<$ when $>33 x$ and the minority forms are $<$ wen $>5 x$, <whan $>4 x,<$ wan $>3 x$, and there are two abbreviated forms occurring once each: $<$ when $>$ and $<$ whan $>$. CULKk.1.3 (part 11), on the other hand, does not have any forms with medial $<\mathrm{e}>$, and all the occurrences for this item but one have some kind of abbreviation: $<\mathrm{wh}^{\wedge} \mathrm{a}^{\wedge} \mathrm{n}>13 \mathrm{x},<\mathrm{wh}^{\wedge} \mathrm{a}^{\wedge} \mathrm{ne}>8 \mathrm{x},<$ whan $n e>4 \mathrm{x},<\mathrm{wh}^{\wedge} \mathrm{a}^{\wedge} \mathrm{nne}>1 \mathrm{x}$, $<$ whane $>1 \mathrm{x}$, and $<$ whane $>1 \mathrm{x}$. Most of the occurrences for this item are spelled with a suprascript $<a>$, while other abbreviations imply a suspended nasal or an omitted vowel. It seems obvious that the scribe chose different ways for performing the same task in either manuscript. He does not seem to have his own system for abbreviating common words. The most obvious reason for doing this might have been to try to follow the same system he had in both his exemplars, which produced disparate outputs in both works.

All the evidence for the forms and features discussed above seems to indicate that the aspect of the language in Hand B in Hatt50 differs in many respects from that of CULKk.1.3. There is a lot of common ground, but at the same time there are some points where both productions are quite far apart and in some extreme cases the scribe produces variants that do not seem to have coincided in place, being dialectally distant. This distance may have been brought about by the scribe's proximity in each of his pieces to his original copy, by having remained faithful to his model, although within the limits permitted by his adaptability and wide repertoire. 


\section{Dialectal variation: Fitting of scribal features}

It would be desirable to be able to locate the origin of this scribe by means of the linguistic features shared by both texts. However, many of his characteristics appear widely distributed to be able to reach reliable conclusions, while others are highly restricted because the number of attestations in the e-LALME sources is low. Fitting an assemblage of some of the forms and features which are common in both productions (see Table 1) points to two possible localisations for the scribe: (1) a large area in the East part of the country including Norfolk, Suffolk, Essex, and areas of Cambridgeshire; (2) an area in the West Midlands that includes the counties of Gloucestershire and South Herefordshire and Worcestershire.

Table 1. Common features

\begin{tabular}{l|l} 
PDE FORM & \\
\hline IF & 3yf \\
\hline AGAINST & azenste \\
\hline CHURCH & chirch \\
\hline THEIR & her \\
\hline THEM & hem \\
\hline 'h' added initially & - \\
\hline etymological 'h' omitted & - \\
\hline use of 'v' for 'w' & - \\
\hline use of 'wh' for 'w' & - \\
\hline
\end{tabular}

When fitting both texts separately, I used both majority and minority forms since, as stated previously, minority forms could easily be more spontaneous forms. I created separate assemblages for the fitting of each of the two texts. In each assemblage there are features which are not common in both texts (see Tables 2 and 3). The results of the fitting led to the following conclusions: (1) the features of the language of Hatt50 fit together in the South Essex area and in London; and (2) CULKk.1.3's distinctive features fit either in the area of London, Essex, and South Hertfordshire or in Warwickshire. If we put these features together with the common ones there are some incompatible areas. Essex is the only county in which many of these features have been found to 
coexist; however, there are not any LPs in the e-LALME sources containing these assemblages or even geographically close texts that might contain all or most of these elements.

Table 2. Assemblage 1 (Hatt50)

\begin{tabular}{l|l} 
PDE form & \\
\hline IF & yf \\
\hline AGAIN & agayne / azenne \\
\hline BEFORE & to-for / be-for / a-fore \\
\hline MUCH & moche / miche / mykill \\
\hline CHURCH & cherch \\
\hline DEATH & dehet \\
\hline FIRE & fere \\
\hline IT & hit \\
\hline THEIR & theyre / their \\
\hline THEM & them \\
\hline 3sg pres ind & -hit / -ht / - t \\
\hline wk pret / ppt ending & -it \\
\hline
\end{tabular}


Table 3. Assemblage 2 (CULKk.1.3)

\begin{tabular}{l|l} 
PDE form & \\
\hline IF & if / iff / 3 iff / iffe \\
\hline AGAIN & azein/e \\
\hline BEFORE & beforn \\
\hline MUCH & muche \\
\hline CHURCH & church \\
\hline DEATH & deith / deth / dede \\
\hline FIRE & fier \\
\hline IT & it \\
\hline ARE & bein \\
\hline MANY & manye \\
\hline
\end{tabular}

\section{Concluding remarks}

The study of the two texts carried out in this paper leads to the following conclusions. First, the paleographical descriptions have shown that it is highly probable that these two texts share a scribe, although the repertoire of figurae for different letters may vary with respect to the degree of formality in each of his productions. Given this, the analysis of the linguistic characteristics of the two texts has shown that a professional scribe in the $15^{\text {th }}$ century, who was accustomed to copying texts of a different nature with different formal and linguistic characteristics, can create copied texts with very different linguistic profiles. All the professional scribes involved in copying the texts discussed above seem to have had a broad linguistic repertoire with a broad range of variant spellings and a great flexibility to adapt to the text they were copying. The result is manuscripts that contain a large number of features brought from their models, but also features that may be the result of a more spontaneous action. Their versatility sometimes makes it impossible to distinguish which of the characteristics of a text belonged to the scribe's spontaneous usage and which were inherited. The linguistic analysis in cases like this is always inconclusive 
for scribal identification and cannot be used to assign a text to any particular scribe. Paleographical analysis has to provide the decisive data on this matter since the linguistic characteristics of many $15^{\text {th }}$-century texts can be misleading and, therefore, cannot be used as primary evidence for these purposes. The LPs for two different texts written by the same scribe may look inconsistent and may even contain elements that might be incompatible from a dialectal point of view. However, localising texts copied in the $15^{\text {th }}$ century can sometimes be difficult because of what Samuels (1981) called 'colourless regional' language. The evidence in these texts and others indicates that some of the forms with a widespread distribution in the $15^{\text {th }}$ century are not good dialect indicators even if many of them are not forms that eventually became standard. The linguistic result of a $15^{\text {th }}$-century scribe's output with such linguistic character does not necessarily have to be a 'Mischsprache' as defined by Benskin \& Laing (1981). As shown above, it is possible to broadly localise a comprehensive assemblage of features drawn from more than one input (scribe and exemplar), albeit to a large area (Essex and neighbouring areas).

Our scribe might have followed different strategies when copying either prose or verse. Copying a poetic text poses different constraints from copying prose, even more so if the text was written in a variety substantially different from his own that might compel a more radical effort of 'translation' towards his spontaneous usage. Occasionally, the changing of morphological forms or features required a sophisticated alteration in the structure of the text since any change can break the rhyme or rhythm of the piece. In those cases, the scribe might have chosen not to alter the shape of the original word even if it was alien to him. The result of this strategy is that in CULKk.1.3 there is a higher level of consistency in many items as it seems that he was trying to be more faithful to his source. However, even when copying prose texts, he respects and embodies the form in his text. The act of translating into his own dialect seems to have been only partially performed. Yet, as we do not know what his source manuscripts were, it is impossible to figure out his behaviour or attitude if the form he encountered was completely alien to him.

Regarding Mooney \& Matheson's (2014: 74) claim that Hand B "is easily influenced by forms in his exemplars, and that the occasional resort to spellings associated with the repertoire of the Beryn Scribe suggests that some of these exemplars were prepared by him", this study supplies data to confirm that he was relatively faithful to his sources, but I have not found any evidence for the second part of the claim. Our scribe shares certain forms and features with the Beryn Scribe, but for some others they are radically different. There is no 
evidence that indicates that the Beryn Scribe prepared any exemplars used by Hands B and C. I have shown that Hands B and C have similar characteristics that might have been inherited from their exemplar/s, and that the Beryn Scribe differs from them in a significant number of cases.

In Carrillo-Linares \& Williamson (2020) the conclusions for the Beryn Scribe's copying approach are not different from the conclusions in the analysis of this scribe's copying practice. As in the Beryn Scribe's production, there is a tendency to respect a great deal of what he found in his exemplars, and the language of his texts was highly dependent on individual textual histories. His experience as a professional copyist must have caused him to augment his repertoire with characteristics inherited from his exemplars reproducing them to greater or lesser degree if they resembled those found in the manuscripts he later copied. Throughout their copying career $15^{\text {th }}$-century scribes became accustomed to certain forms that were not incompatible with their spoken language in many cases, and even though these forms would not have been the most spontaneous ones, they were perfectly acceptable and became, first, part of their passive language and, eventually, these forms ended up being familiar and used with the same facility as those they first learnt.

\section{References}

MANUSCRIPT SOURCES

Ann Arbor, University of Michigan, Hatcher Library, 225

Cambridge, University Library Kk.1.3 (parts 10 and 11)

London, British Library Harley 1337

London, British Library Harley 6251

Manchester, John Rylands Library English 63

Northumberland, Alnwick Castle 455

Oxford, Bodleian Library, Hatton 50

Oxford, Bodleian Library, Rawlinson C. 901

Oxford, Bodleian Library, Tanner 11

Oxford, St John's College 57

Philadelphia, Rosenbach Museum and Library 1084/2

Princeton, Firestone Library 100 


\section{SECONDARY SOURCES}

Benskin, M. \& M. Laing 1981: Translations and Mischsprachen in Middle English Manuscripts. In M. Benskin \& M. L. Samuels eds. So Meny People Longages and Tonges: Philological Essays in Scots and Mediaeval English Presented to Angus McIntosh. Edinburgh, Middle English Dialect Project: 55-106.

Carrillo-Linares, M. J. \& K. Williamson 2019: A Reconsideration of the Dialectal Provenance of the Prick of Conscience in Oxford, St John's College, 57. Anglia 137.2: 303-350.

Carrillo-Linares, M. J. \& K. Williamson 2020: The Linguistic Character of Manuscripts Attributed to the So-called 'Beryn Scribe': A Comparative Study. In L. Wright ed. The Multiple Origins of Standard English. Berlin \& New York, Mouton de Gruyter: 87-139.

Christianson, C. P. 1989: Evidence for the Study of London's Late Medieval Manuscript-Book Trade. In J. Griffiths \& D. Pearsall eds. Book Production and Publishing in Britain, 1375-1475. Cambridge, Cambridge University Press: 87-108.

e-LALME: An Electronic Version of A Linguistic Atlas of Late Mediaeval English. 2013: M. Benskin, M. Laing, V. Karaiskos \& K. Williamson. Edinburgh, The University of Edinburgh. http://www.lel.ed.ac.uk/ihd/elalme/elalme.html. [Accessed from September 2013 to June 2020]

Horobin, S. 2009: The Edmund-Fremund Scribe Copying Chaucer. Journal of the Early Book Society 12: 193-203.

Horobin, S. \& L. R. Mooney 2004: A 'Piers Plowman' Manuscript by the Hengwrt/Ellesmere Scribe and its Implications for London Standard English. Studies in the Age of Chaucer 26: 65-112.

Laing, M. 2000: The Linguistic Stratification of the Middle English Texts in Oxford, Bodleain Library, Ms Digby 86. Neuphilologische Mitteilungen 101.4: 523-569.

LALME: A Linguistic Atlas of Late Medieval English. 1986: A. McIntosh, M. L. Samuels \& M. Benskin [with the assistance of M. Laing and K. Williamson]. Aberdeen, Aberdeen University Press.

McIntosh, A. 1974: Towards an Inventory of Middle English Scribes. Neuphilologische Mitteilungen 75: 602-624. [Reprinted in M. Laing ed. 1989: Middle English Dialectology: Essays on Some Principles and Problems. Aberdeen, Aberdeen University Press: 46-63.]

Matheson, L. 1998: Prose Brut: The Development of a Middle English Chronicle. Tempe (Arizona), Medieval and Renaissance Texts and Studies, 180.

Mooney, L. R. 2006: Chaucer's Scribe. Speculum 81.1: 97-138.

Mooney, L. R. \& L. Matheson 2003: The Beryn Scribe and his Texts: Evidence for Multiple-Copy Production of Manuscripts in Fifteenth-Century England. The Library 4.4: 347-370.

Mooney, L. R., S. Horobin \& E. Stubbs. Late Medieval English Scribes https://www.medievalscribes.com. ISBN 978-0-9557876-6-9. 
Mosser, D. 2010. The Paper Stocks of the Beryn Scribe. Journal of the Early Book Society for the Study of Manuscripts and Printing History 13: 63-93.

Mosser, D. \& L. R. Mooney 2014: More Manuscripts by the Beryn Scribe and his Cohort. The Chaucer Review 49.1: 39-76.

Mosser, D. \& L. R. Mooney 2016: The Case of the Hooked-g Scribe(s) and the Production of Middle English Literature, c. 1460 - c. 1490. Chaucer Review 51: 131150.

Samuels, M. L. 1981: Spelling and Dialect in the Late and Post-Middle English Periods. In M. Benskin \& M. L. Samuels eds. So Meny People Longages and Tonges: Philological Essays in Scots and Mediaeval English Presented to Angus McIntosh. Edinburgh, Middle English Dialect Project: 43-54.

Summary Catalogue, Vol 2, Part II. 1937: H. H. E. Craster \& N. Denholm-Young. Summary Catalogue of Western Manuscripts in the Bodleian Library at Oxford, Vol 2, part II (Collections and Miscellaneous Mss Acquired during the Second Half of the $17^{\text {th }}$ Century), not. 3491-8716. Oxford, Clarendon Press.

Taylor, A. 2003: Manual to Miscellany: Stages in the Commercial Copying of Vernacular Literature in England. The Yearbook of English Studies 33: 1-17.

Warner, L. 2018: Chaucer's Scribes. London Textual Production, 1384-1432. Cambridge, Cambridge University Press. 
Appendix 1. Cambridge, Cambridge University Library, Kk.1.3

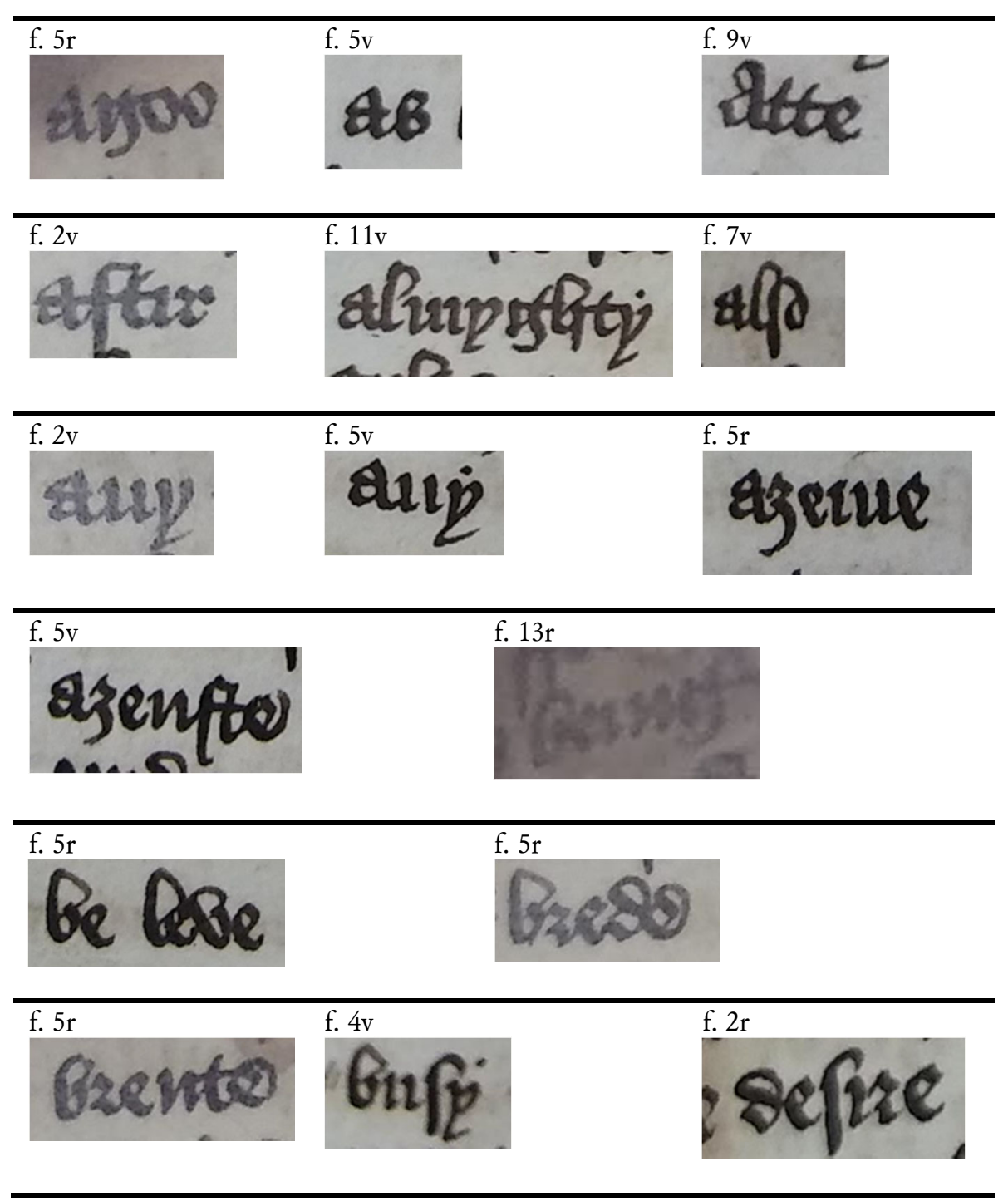


162 María José Carrillo-Linares

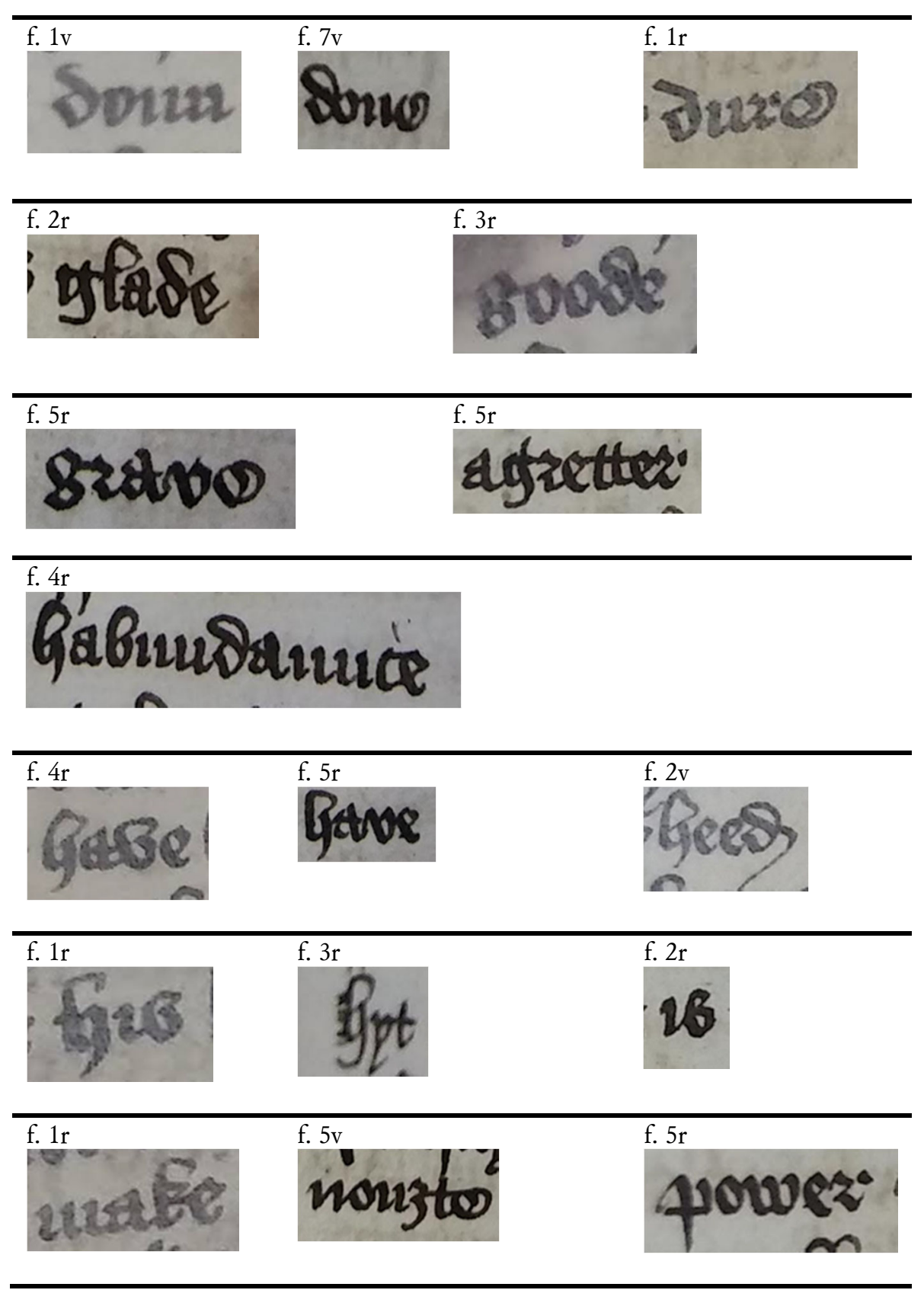




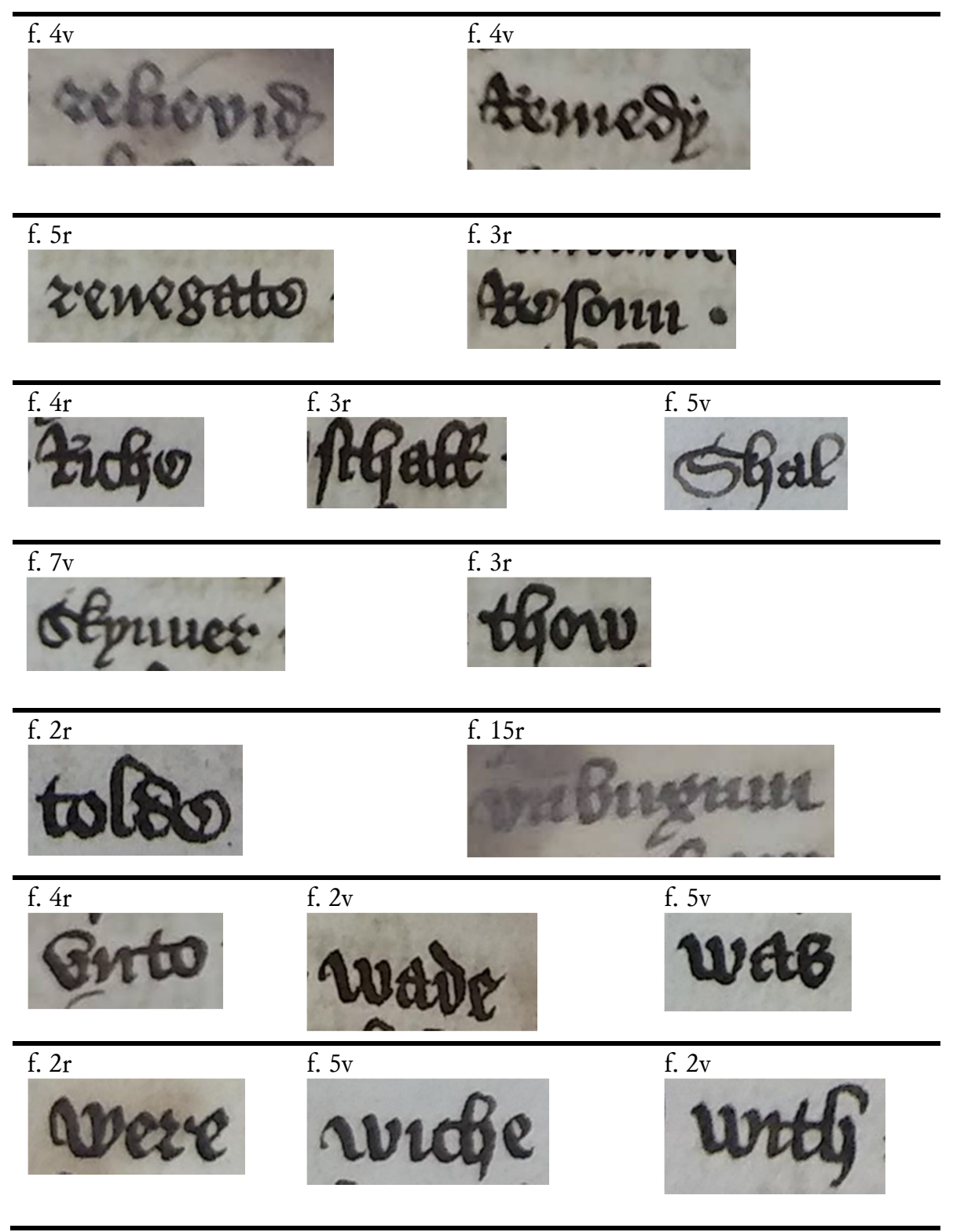


164 María José Carrillo-Linares

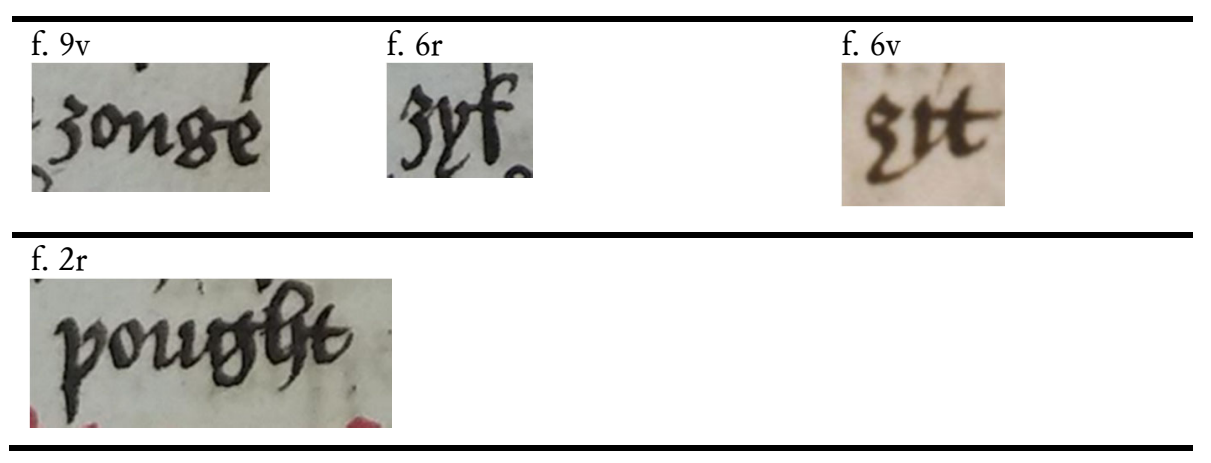


Appendix 2. Oxford, Bodleian Library, Hatton 50 (HAND 2)

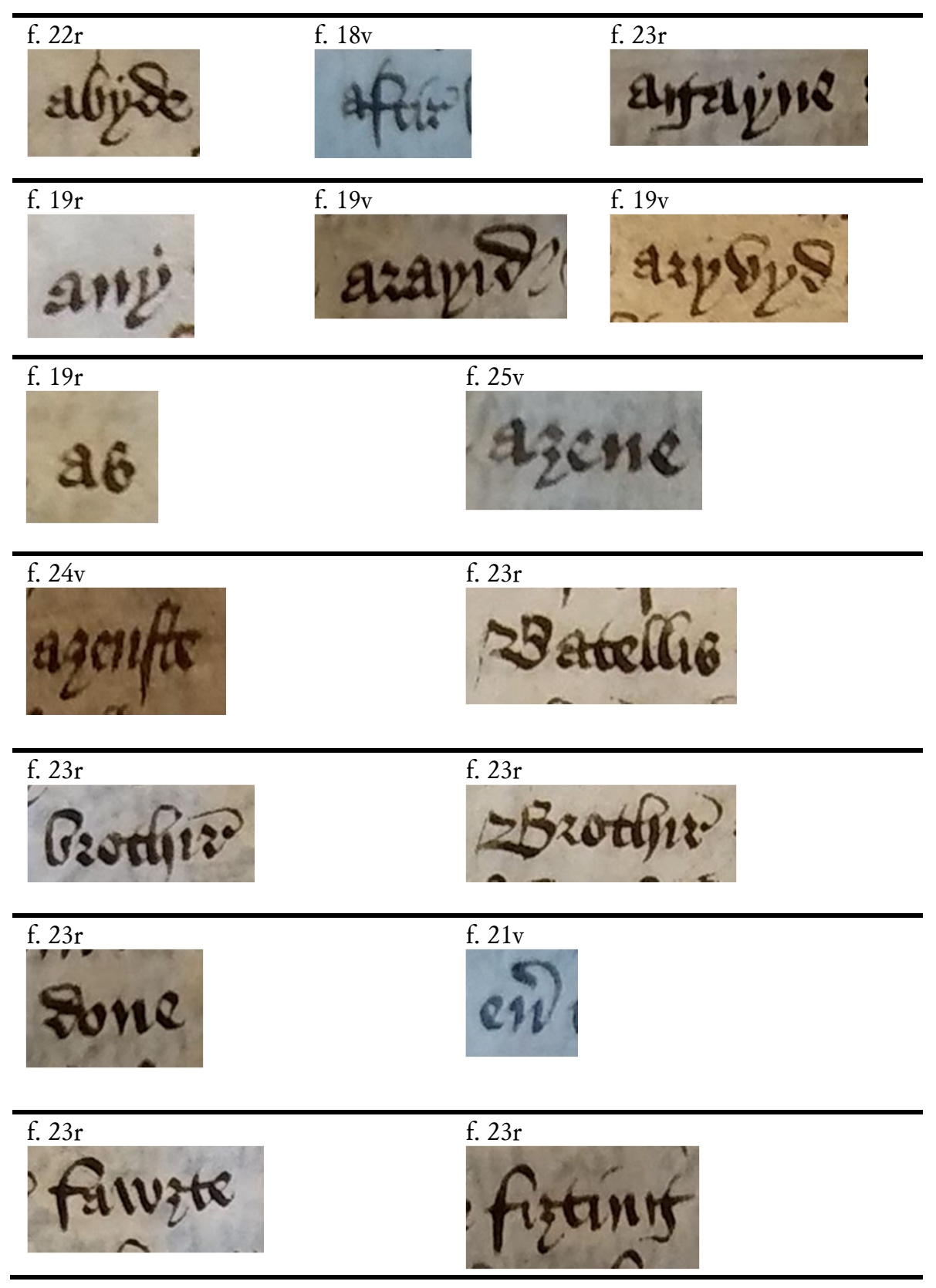



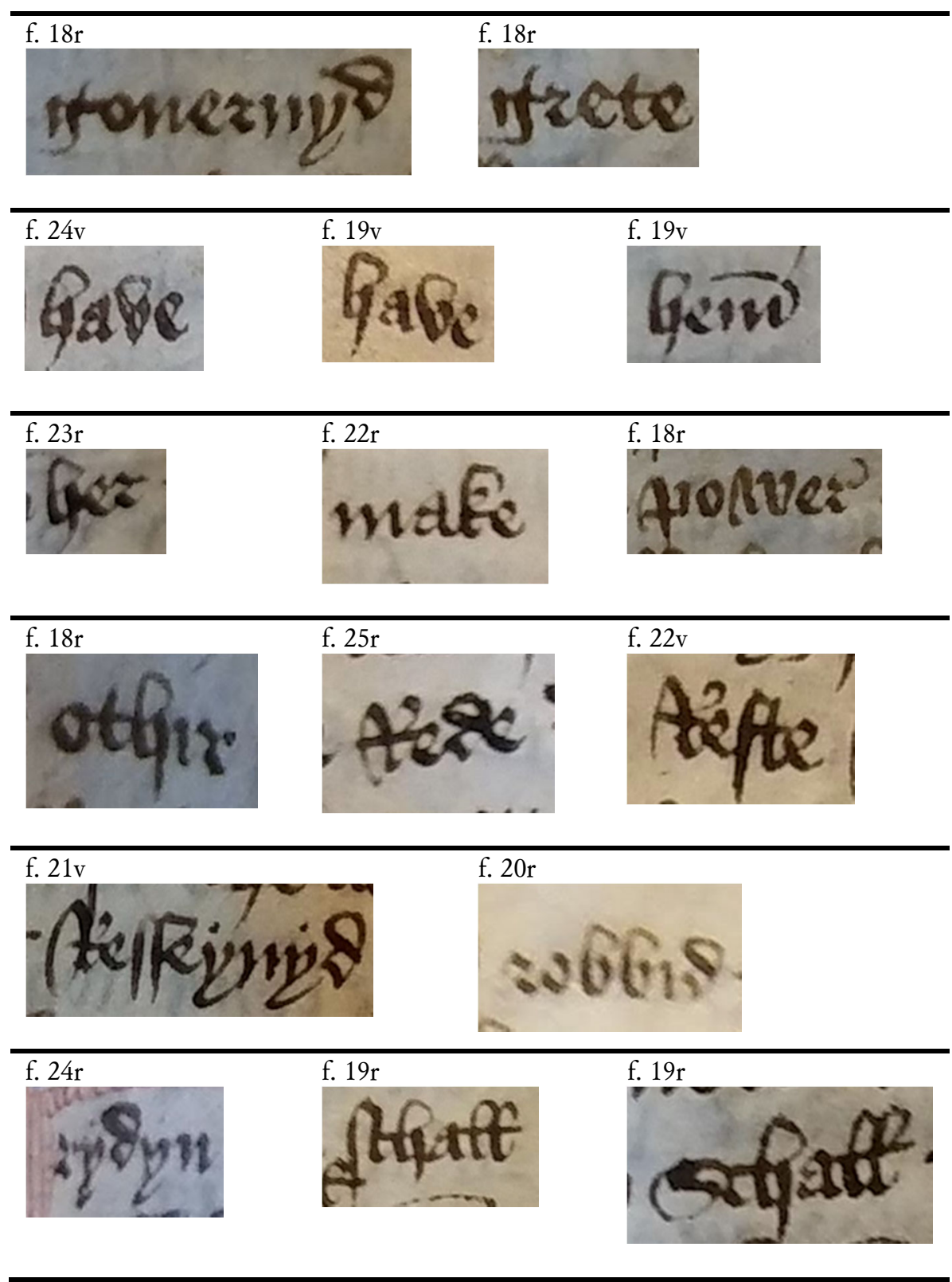


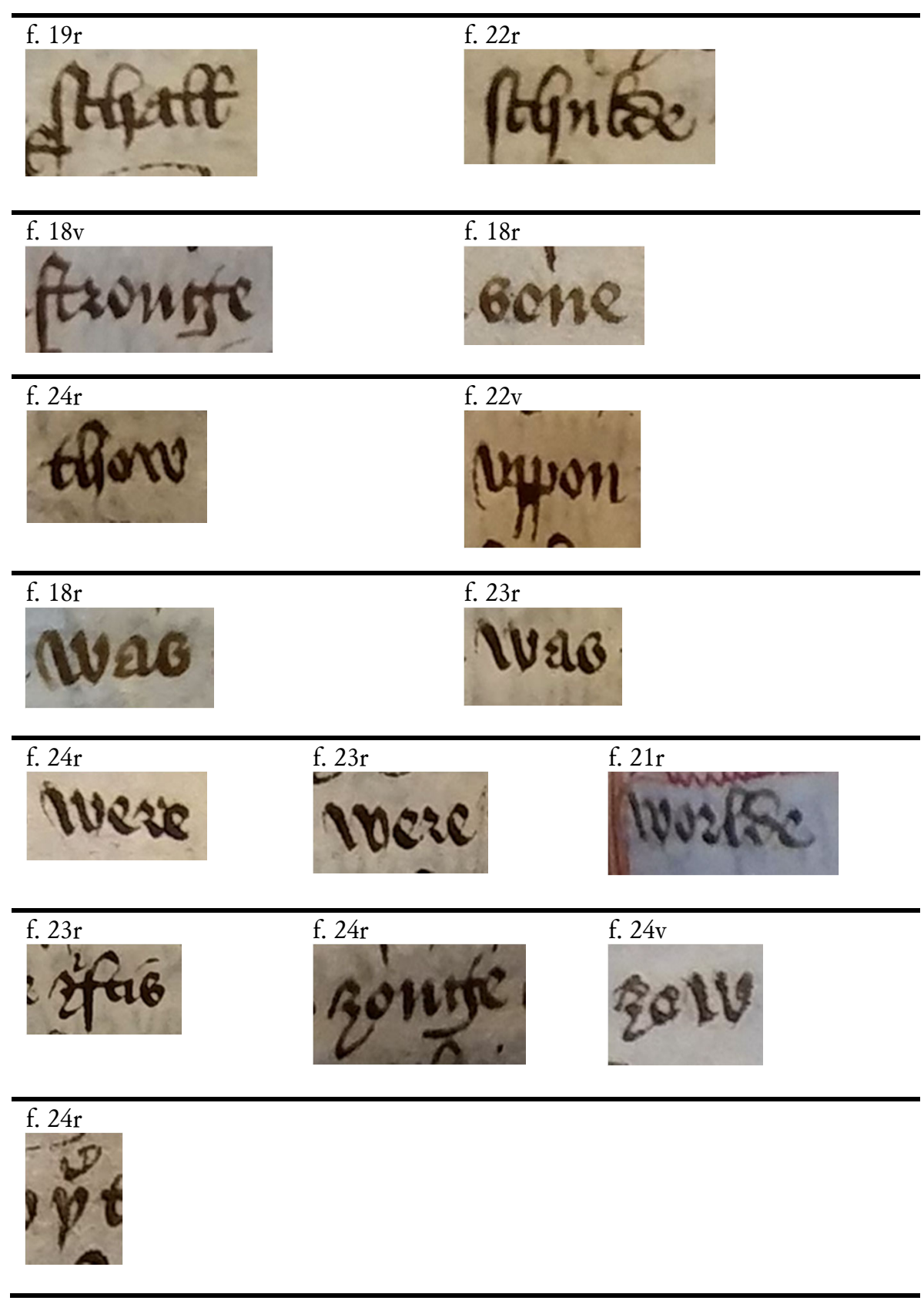


Appendix 3. Comparison of forms from Cambridge, Cambridge University Library, Kk.1.3 and Oxford, Bodleian Library, Hatton 50 (HAND 2)

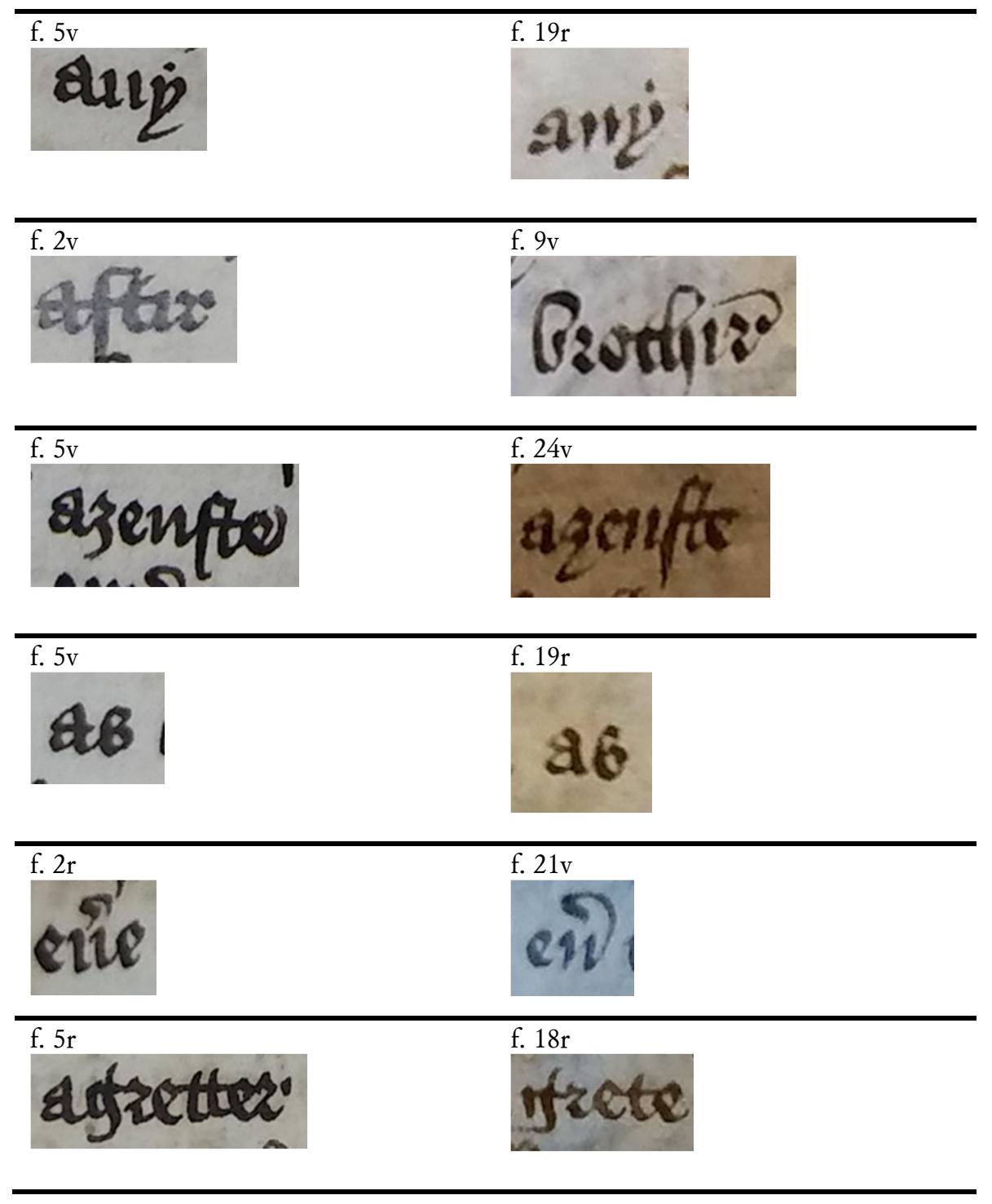




\begin{tabular}{|c|c|}
\hline f. $12 \mathrm{v}$ & f. $23 r$ \\
\hline f. $6 r$ & f. $24 \mathrm{r}$ \\
\hline f. $6 \mathrm{v}$ & f. $24 \mathrm{v}$ \\
\hline f. $4 \mathrm{r}$ & f. $24 \mathrm{v}$ \\
\hline f. $3 r$ & f. $19 r$ \\
\hline f. $1 \mathrm{r}$ & f. 19r \\
\hline f. $7 \mathrm{r}$ & f. $18 \mathrm{r}$ \\
\hline & \\
\hline
\end{tabular}


170 María José Carrillo-Linares

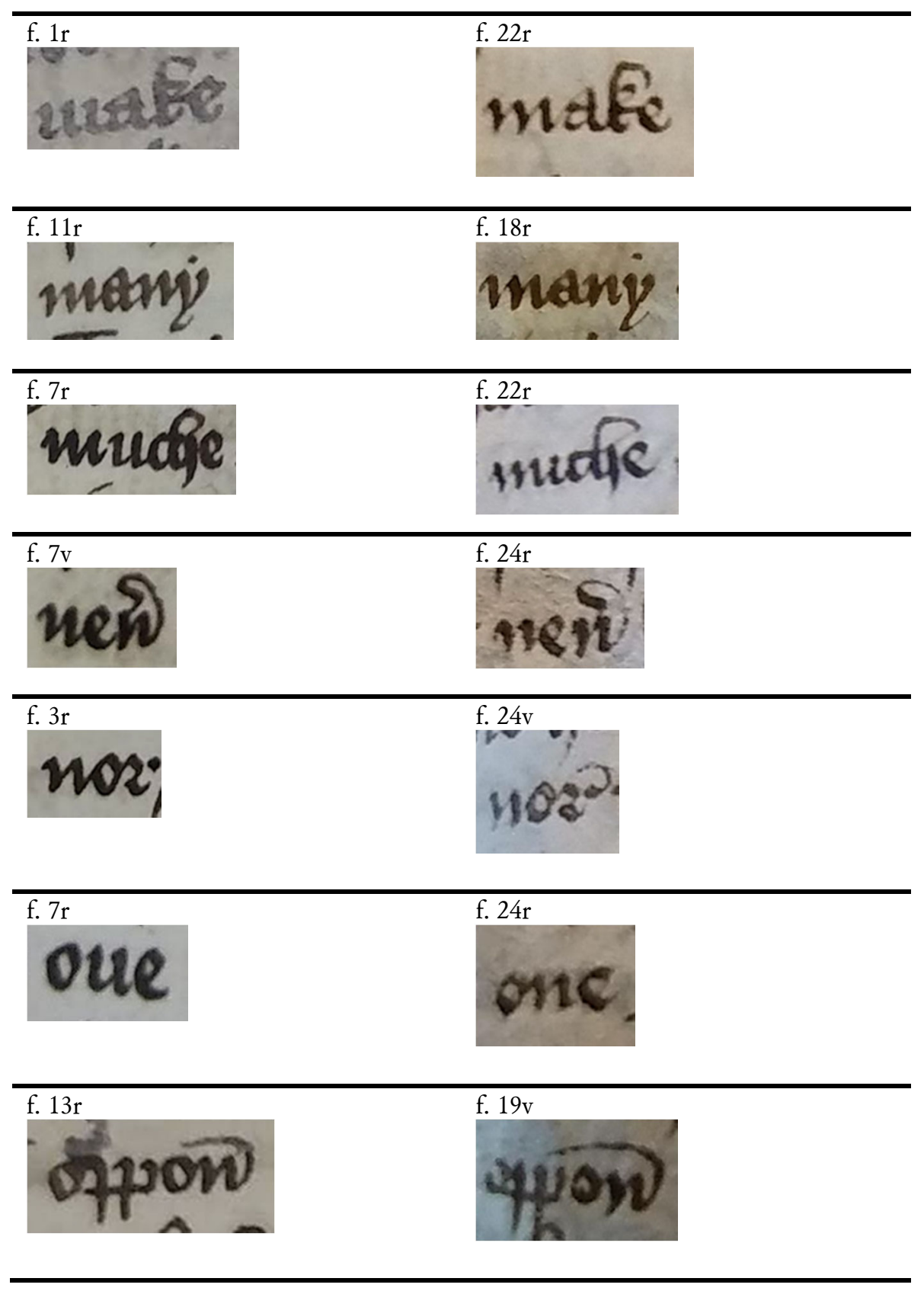




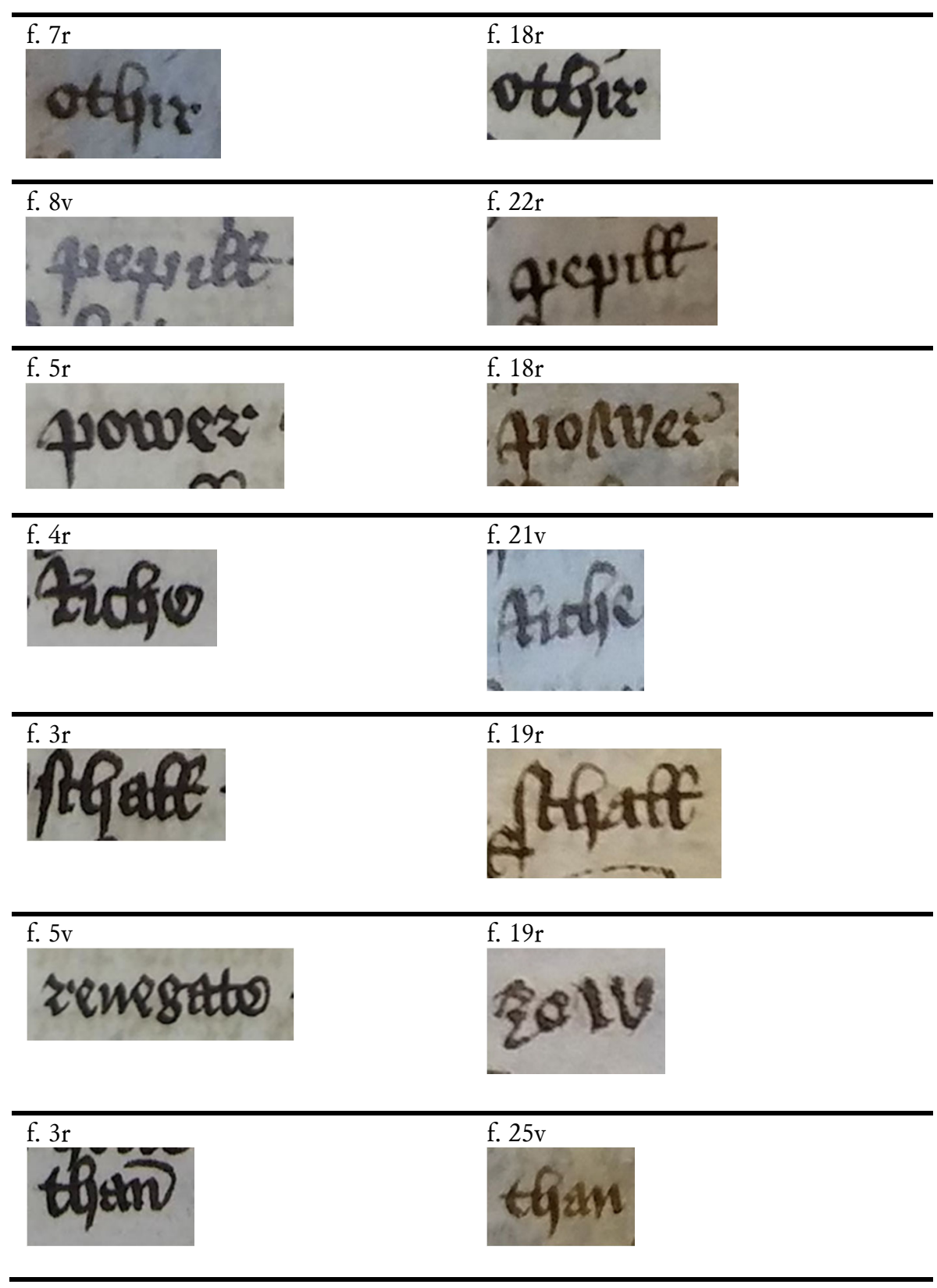


172 María José Carrillo-Linares

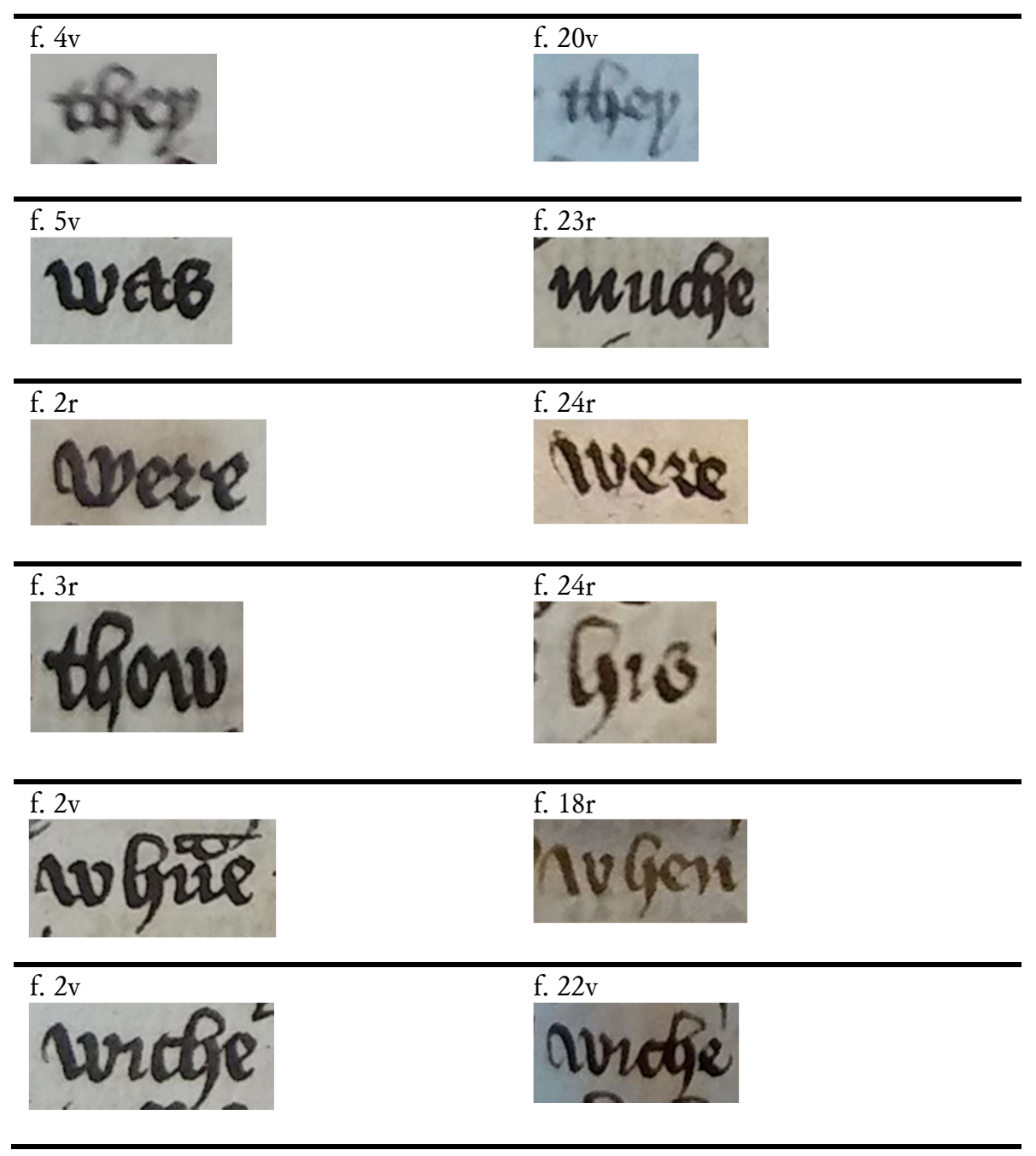

Author's address

Departamento de Filología Inglesa

University of Huelva

Facultad de Humanidades, Campus Universitario, Campus del Carmen

Avenida de las Fuerzas Armadas s/n

21071 - Huelva

Spain

e-mail:mlinares@dfing.uhu.es

received: 22 July 2020

revised version accepted: 7 September 2020 